Review

\title{
Local Treatments in the Unresectable Patient with Colorectal Cancer Metastasis: A Review from the Point of View of the Medical Oncologist
}

\author{
Javier Torres-Jiménez ${ }^{1, *,+}{ }^{\mathbb{C}}$, Jorge Esteban-Villarrubia ${ }^{1,+}$, Reyes Ferreiro-Monteagudo ${ }^{1, \ddagger}$ and Alfredo Carrato ${ }^{2, \ddagger}$ \\ 1 Medical Oncology Department, University Hospital Ramon y Cajal, 28034 Madrid, Spain; \\ elementjorge00@gmail.com (J.E.-V.); reyes-ferreiro@hotmail.com (R.F.-M.) \\ 2 Medical Oncology Department, Ramón y Cajal Health Research Institute (IRYCIS), CIBERONC, \\ Alcalá University, University Hospital Ramon y Cajal, 28034 Madrid, Spain; acarrato@telefonica.net \\ * Correspondence: javier.torres.jim@gmail.com \\ + These authors have contributed equally to this work as co-first authors. \\ $\ddagger$ These authors have contributed equally to this work as co-second authors.
}

check for updates

Citation: Torres-Jiménez, J.; Esteban-Villarrubia, J.;

Ferreiro-Monteagudo, R.; Carrato, A. Local Treatments in the Unresectable Patient with Colorectal Cancer

Metastasis: A Review from the Point of View of the Medical Oncologist. Cancers 2021, 13, 5938. https:// doi.org/10.3390/cancers13235938

Academic Editor: Constantinos T. Sofocleous

Received: 4 October 2021

Accepted: 21 November 2021

Published: 25 November 2021

Publisher's Note: MDPI stays neutral with regard to jurisdictional claims in published maps and institutional affiliations.

Copyright: (c) 2021 by the authors. Licensee MDPI, Basel, Switzerland. This article is an open access article distributed under the terms and conditions of the Creative Commons Attribution (CC BY) license (https:/ / creativecommons.org/licenses/by/ $4.0 /)$.
Simple Summary: Local treatments represent a potential curative approach in the patient with liver metastases of colorectal origin. It is important for all the team involved in patient care to know and understand which patients are suitable for this approach and the expected results of these treatments. This review is intended to focus (without neglecting the technical issues of these techniques) in clinical aspects, to help other clinicians to seek the best available evidence to guide their decisions and advocate for the best possible treatment for the patient.

Abstract: For patients with isolated liver metastases from colorectal cancer who are not candidates for potentially curative resections, non-surgical local treatments may be useful. Non-surgical local treatments are classified according to how the treatment is administered. Local treatments are applied directly on hepatic parenchyma, such as radiofrequency, microwave hyperthermia and cryotherapy. Locoregional therapies are delivered through the hepatic artery, such as chemoinfusion, chemoembolization or selective internal radiation with Yttrium 90 radioembolization. The purpose of this review is to describe the different interventional therapies that are available for these patients in routine clinical practice, the most important clinical trials that have tried to demonstrate the effectiveness of each therapy and recommendations from principal medical oncologic societies.

Keywords: metastatic colorectal cancer; interventional oncology in metastatic colorectal cancer; tumor ablation; liver intraarterial hepatic therapies; DEBIRI TACE; Yttrium-90

\section{Introduction}

Colorectal cancer (CRC) is the third cancer in incidence rate in adults and the second most common cause of cancer-related death in Europe [1-3]. Metastatic disease to the liver is present in $20 \%$ of patients with CRC at the time of diagnosis and appears in an additional $40 \%$ over the course of earlier-stage disease treated with resection. In $30 \%$ of patients, the liver is the only site of metastatic disease [4]. Liver resection or surgical metastasectomy is the best chance of cure for patients with liver metastases of colorectal cancer (LMCRC), especially in liver-limited or oligometastatic disease [5]. The number of metastases accepted as oligometastic disease that would benefit from local treatment is not well established, but the change in prognosis of these patients appears in the 8th American Joint Committee on Cancer (AJCC) staging (M1a: metastases at one site, M1b: metastases at two or more sites).

However, only up to $25 \%$ of eligible patients undergo resection because of the presence of co-morbidities or unresectability. Non-surgical local therapies, loco-regional or 
liver-directed therapies are significant therapies for treatment of LMCRC given the response rates to systemic chemotherapy (QT) alone [6]. Although several modern combinations of treatments (5-fluouracil (5-FU)/leucovorin (LV)/oxaliplatin (FOLFOX), 5FU/LV/irinotecan (FOLFIRI), 5-FU/LV/oxaliplatin/irinotecan (FOLFOXIRI), targeted therapies as anti-epidermal growth factor receptor (EGFR) for RAS wild-type tumors, such as cetuximab and panitumumab and anti-vascular endothelial growth factor (VEGF), such as bevacizumab and aflibercept) have been developed recently, objective response rates (ORR) to first-line treatments for metastatic CRC range from $34 \%$ to $66 \%$, and from $30 \%$ to $40 \%$ for second line [7].

The election of the kind of non-surgical local therapy is influenced by several factors: the size and localization of LMCRC, the local control rates achieved, the invasiveness of the technique, the local expertise regarding the use of each therapy and patients' preferences [5]. Non-surgical local treatments in LMCRC require a multidisciplinary approach, including medical oncologists, surgical oncologists, radiation oncologists and interventional radiologists.

Non-surgical therapies in LMCRC are classified in different ways. The most useful classification is based on how the treatment is administered (Table 1). Local treatments are applied directly on hepatic parenchyma, and locoregional therapies facilitate the infusion of diverse agents into hepatic vessels. Goal of treatment is also useful to classify these therapies. It is important to note that local ablative therapies should be offered to patients in which all visible disease can be treated with a curative intent, while loco-regional therapies are usually offered to non-resectable and non-ablatable patients with LMCRC in order to improve local control along with systemic therapy, as will be discussed below.

Table 1. Types of non-surgical local treatments in liver metastases of colorectal cancer.

\begin{tabular}{|c|c|}
\hline \multicolumn{2}{|c|}{ Local Treatments } \\
\hline Thermal & $\begin{array}{c}\text { Radiofrequency ablation (RFA) } \\
\text { Microwave ablation (MWA) } \\
\text { Cryoablation } \\
\text { Laser interstitial thermal therapy (LITT) * } \\
\text { High-intensity focused ultrasound (HIFU) * }\end{array}$ \\
\hline Non-thermal & $\begin{array}{c}\text { Radiotherapy (SBRT) } \\
\text { Irreversible electroporation (IRE) * }\end{array}$ \\
\hline \multicolumn{2}{|c|}{ Loco-Regional Treatments } \\
\hline Embolization & $\begin{array}{c}\text { Bland particulate embolization * } \\
\text { Chemoinfusion or hepatic artery infusion } \\
\text { Transarterial chemoembolization } \\
\text { Radioembolization }\end{array}$ \\
\hline
\end{tabular}

* Laser interstitial thermal therapy (LITT), high-intensity focused ultrasound (HIFU) and bland particulate embolization have not been used in large scale for LMCRC.

Local ablative therapies (LAT) produce thermal damage to tissues. They include radiofrequency ablation (RFA), microwave ablation (MWA), laser ablation and ultrasound ablation, which produce damage with the increase in temperature, whereas cryoablation freezes tissue, which leads to cell death. Irreversible electroporation or percutaneous instillation of ethanol are under investigation in LMCRC.

Stereotactic body radiotherapy (SBRT) consists in a precise delivery of high doses of radiation to an extracranial target in a small number of fractions, sparing surrounding critical tissue. SBRT needs accurate immobilization, a method to manage the respiratory motion of the target and image guidance to ensure proper alignment and delivery of the radiation dose $[8,9]$.

Locoregional therapies are distributed through the hepatic artery (embolization procedures or hepatic arterially directed therapies) for the treatment of LMCRC. These therapies include bland particulate embolization, chemoinfusion, chemoembolization and radioembolization. The health liver receives $80 \%$ of its blood supply from the portal vein and $20 \%$ 
from the hepatic artery but, in contrast, hepatic malignancies receive $80 \%$ of their blood supply from the hepatic artery. The dual blood supply to the liver explains the effectiveness of hepatic arterially directed therapies.

This review focuses only in two kinds of non-surgical local treatments in LMCRC: ablative local therapies and hepatic arterially directed therapies. The main clinical trials and retrospective comparations that have tried to demonstrate the effectiveness of each therapy and recommendations from principal medical oncologist societies are described.

\section{Definition of Unresectability}

Unresectable LMCRC are the patients with multiple and bilobar disease for whom R0 resection cannot be performed, leaving at least 20-25\% of total liver volume with adequate inflow, outflow and biliary drainage [10]. There are no criteria for distinguishing between the patients for whom purely palliative treatment and those for whom potentially curative treatment is appropriate. Patients with LMCRC only have to be considered definitively unresectable after being treated with optimal systemic treatment over 2-4 months, so the possibility for resection is not missed in patients who a priori have a low chance of further $\mathrm{R} 0$ resection [11,12].

\section{Conversion Chemotherapy to Improve Resectability}

Conversion therapy could be defined as the use of chemotherapy to downstage the tumor, allowing to achieve a $\mathrm{R} 0$ resection in patients deemed unresectable because of high tumor burden. In this setting, highly active regimes with high response rates (RR) and minimum time to response are considered the best options, as a positive correlation has been shown between RR and resectability. However, this result has to be interpreted with caution, as regimes included in the study are different to those used nowadays [13].

Patients receiving conversion therapy should be reevaluated every two months [14] in order to avoid unnecessary toxicity for the liver, as oxaliplatin and irinotecan, two of the most used drugs in this setting, are associated with sinusoidal obstruction syndrome, non-cirrhotic portal hypertension and steatosis, respectively [15-17]. There are unresolved issues, such as the optimal time for reevaluation, the method of radiological evaluation, not only regarding the imaging test, but also the response criteria. Anti-angiogenic treatment is associated not only with changes in the size of lesions, but also morphological changes. Criteria based on these modifications have been described and have shown correlation with pathological response and survival [18]. As the efficacy of systemic drugs and agents are increasing, patients with LMCRC must receive $2-4$ months of systemic treatment before considering them completely unresectable. At this time, the maximal tumor shrinkage is deemed to have occurred in most cases. No patient should lose the opportunity of an eventual resection although the a priori probability is deemed to be low [12].

Treatment options are chosen based on patient-related factors, the mutational profile of the tumor, and toxicity profiles of the chemotherapeutic drugs used. These drugs are given in doublets composed of a fluoropyrimidine with oxaliplatin, irinotecan or both. They are known as FOLFOX (5-FU + oxaliplatin), CAPOX (capecitabine + oxaliplatin), FOLFIRI (5-FU + irinotecan) or FOLFOXIRI (5-FU + oxaliplatin + irinotecan). All patients should have their RAS or BRAF mutation status determined [5,19]. Anti-EGFR therapy is not effective in mutant RAS patients, and the evidence increasingly suggests that BRAF V600E mutation is associated with poor response to panitumumab or cetuximab [20]. HER2 amplifications are also a matter of debate, as increasing evidence suggests that these patients are not expected to respond to anti-EGFR treatment [21]. NCCN guidelines recommend determination of HER2 amplification in all RAS and BRAF native patients, but ESMO guidelines do not recommend this determination outside clinical research. The role of HER2 in the conversion therapy setting is yet to be established [5,11,19]. High satellite instability and mismatch repair deficiency (MSI-H/dMMR) is predictive of response to immunotherapy but its role in conversion therapy is not defined. Sideness of the primary 
tumor is an important factor that must be taken into account as right-sided colon cancer is less responsive to anti-EGFR treatment. [22].

Table 2 summarizes the main trials of conversion chemotherapy, showing response rates and liver resection rates. Ye et al. showed that patients in either treatment arm undergoing hepatic resection had a significative longer median survival time than those who did not (46.4 versus 25.7 months for the cetuximab arm and 36.0 versus 19.6 months for the chemotherapy alone arm) [23]. A similar trend was shown in the PLANET-TTD trial, with a significative prolongation in OS in resected patients (52 months vs. 36 months) [24]. ESMO guidelines recommend for patients without RAS mutations and left-sided primary a chemotherapy doublet with an anti-EGFR antibody, as it is associated with a higher response rate. For right sided primary, a chemotherapy doublet or triplet (if appropriate) with bevacizumab is recommended. For RAS mutated tumors, a chemotherapy doublet or triplet is recommended. For BRAF mutated tumors, as BRAF is associated with poor prognosis, chemotherapy triplet plus bevacizumab is their recommendation [19]. The role of hepatic arterially directed therapies in conversion treatment are discussed below.

Table 2. Main trials of conversion chemotherapy.

\begin{tabular}{|c|c|c|c|c|c|c|}
\hline Study & Year & $n$ & Study Population & Treatment & $\mathbf{R} \mathbf{R}$ & $\begin{array}{c}\text { Liver } \\
\text { Resection Rate }\end{array}$ \\
\hline CELIM [25] & 2010 & 106 & No molecular selection & FOLFOX6/FOLFIRI + Cet & $\begin{array}{l}\text { All patients: } 63 \% \\
\text { KRAS ex2wt: } \\
70 \%\end{array}$ & $33 \%$ \\
\hline GONO [26] & 2010 & 30 & No molecular selection & FOLFOXIRI + Bev & $80 \%$ & $40 \%$ \\
\hline BOXER [27] & 2011 & 46 & No molecular selection & $\mathrm{CAPOX}+\mathrm{Bev}$ & $78 \%$ & $40 \%$ \\
\hline Ye et al. [23] & 2013 & 138 & KRAS exon 2 wild-type & FOLFIRI/FOLFOX $\pm \mathrm{Bev}$ & $57 \%$ vs. $29 \%$ & $26 \%$ vs. $7 \%$ \\
\hline OLIVIA [28] & 2015 & 80 & No molecular selection & $\begin{array}{l}\text { FOLFOXIRI + Bev vs. } \\
\text { FOLFOX + Bev }\end{array}$ & $81 \%$ vs. $62 \%$ & $49 \%$ vs. $23 \%$ \\
\hline PLANET-TTD [24] & 2017 & 77 & KRAS exon 2 wild type & $\begin{array}{l}\text { FOLFOX + Pmab vs. } \\
\text { FOLFIRI + Pmab }\end{array}$ & $74 \%$ vs. $67 \%$ & $34 \%$ vs. $46 \%$ \\
\hline VOLFI [29] & 2019 & 99 & $\begin{array}{l}\text { KRAS exon } 2 \text { wild type. } \\
\text { Other RAS mutations } \\
\text { included but excluded } \\
\text { from the analysis }\end{array}$ & $\begin{array}{l}\text { FOLFOXIRI + Pmab vs. } \\
\text { FOLFOXIRI }\end{array}$ & $87.3 \%$ vs. $60.6 \%$ & $\begin{array}{c}\text { Global } \\
\text { population: } \\
33.3 \% \text { vs. } 12.1 \% \\
\text { Convertible } \\
\text { population: } \\
75 \% \text { vs. } 36.4 \% \text {. }\end{array}$ \\
\hline
\end{tabular}

Abbreviations: Bev—bevacizumab, CAPOX—capecitabine + oxaliplatin, Cet—cetuximab, FOLFIRI-5-FU + irinotecan, FOLFOX-5-FU + oxaliplatin, FOLFOXIRI-5-FU + oxaliplatin + irinotecan, $n$-number of patients, Pmab-panitumumab, RR-resection rate.

\section{Local Ablative Therapies}

There are many ablative percutaneous therapies, most of them consisting of direct administration of energy to destroy malignant tissue. A percutaneous probe should be placed in the metastatic lesion, all guided by image techniques as computer tomography (CT), magnetic resonance (MR) or ultrasound (US). The most important therapies are radiofrequency ablation (RFA), microwave ablation (MWA) and cryoablation [30]. Guidelines from ESMO support the role of a multidisciplinary team (MDT) in choosing the best treatment option from a "toolbox" of ablative therapies, taking into account some factors such as the size and number of metastases, rates of local control achieved and invasiveness of a particular technique, patient fragility, comorbidity and preferences and the local operator expertise regarding the use of a particular ablative treatment method. Discussion in a MDT is granted in complex cases but it is not mandatory in all cases $[5,19]$. On the other hand, the NCCN guidelines describe different ablative therapies, noting that the most extensive evidence published in the literature is about RFA. However, attention is paid to the growing evidence regarding other techniques, such as MWA, but no clear preference 
on one technique over the other is expressed. The SEOM guideline on LMCRC is in line with NCCN [11,12].

It is important to keep in mind that hepatic resection is only considered for fit patients (no medical contraindications to surgery), with favorable prognostic factors (number of lesions, presence or suspicion of extrahepatic disease, diverse scores) and with technically feasible surgery (diverse and evolving criteria; the most accepted criteria nowadays is whenever a macroscopic resection is feasible while maintaining sufficient liver remnant after the surgery) $[5,19]$. Results from surgery in these patients range from $20 \%$ to $58 \%$ of 5-year overall survival (OS) [31-33], but with 90-day mortality of $4 \%$ and a $40 \%$ of complication rate [34]. Ablative therapies were historically reserved for patients that were not candidates for surgery. Nowadays, it is very important to note that ablative therapies are considered potentially curative therapies in oligometastatic patients amenable to local ablation therapy with adequate margins, either alone or in combination with resection, as long as all visible disease is eradicable, even in patients considered candidates for surgery. This represents a significant change from the previous mindset [11]. In this line, the published literature suggests that ablation may provide acceptable oncologic outcomes for selected fit patients with small liver metastases that can be ablated with sufficient margins [35,36]. A panel of experts also noted the potential role and possible advantages of performing RF ablation during the interval between diagnosis and hepatic metastasectomy. This approach is known as the "test of time". This would allow to cure a significant proportion of patients, to select patients for surgery for whom the ablation had failed, and to spare an unnecessary surgery for patients for whom new lesions appeared over the described interval and would be no longer candidates for surgery. This approach has been also proposed to progressing patients after an initial surgery as a modified test-of-time approach [37-39]. It is also very important to note that ablative therapies can be used in conjunction with surgery with curative intent to achieve complete local control with adequate surgical and ablation margins in patients in whom some lesions are resectable and others not. This is reflected in the three clinical guidelines previously described $[5,11,12,19]$.

\subsection{Radiofrequency Ablation}

RFA consists in the placement of an electrode probe in the metastatic lesion for treatment, producing rapidly alternating electrical currents that produce ionic oscillations in water molecules, leading to the generation of frictional heat. Temperatures in the vicinity of the probe exceed 100 degrees Celsius, leading to instant cell death by thermocoagulation. Two types of RFA devices are usually used. Monopolar (MP) RFA and bipolar (BP) RFA employ a single antenna or two, respectively. Tissue destruction is greater near the probe, as the zone of active tissue heating is limited to a few millimeters near the probe. Blood flow in vessels $>3 \mathrm{~mm}$ can evacuate heat, limiting heat conduction in what is known as the "heat-sink" effect. BP-RFA is less affected by the heat-sink effect compared to MPRFA [40]. Therefore, lesions located adjacent to noble structures, such as the central bile ducts, vessels $>3 \mathrm{~mm}$ and bowels are technically more complicated to correctly ablate. Tissue charring surrounding active elements of the probe also limits heat conduction and can contribute to a suboptimal procedure. Taking into account these technical considerations, the optimal lesions for this treatment are those smaller than $3 \mathrm{~cm}$ and not adjacent to noble structures. Incomplete ablation is more likely with increasing size, but electrodes $10 \mathrm{~mm}$ larger than the target tumor have been proved to successfully ablate larger diameter tumors [41]. Grounded pads placed in the lower extremities of the patient are required to protect from electric discharges. RFA can be conducted percutaneously or intraoperatively, previous to the procedure, concomitantly or after a planned or unplanned incomplete resection [42]. There are different approaches to electrode placement. The open technique is the most invasive approach and can be done concomitantly to liver resection or other simultaneous open procedures. The percutaneous approach is the least invasive procedure and can be performed without general anesthesia. It has is limitations, as lesions located in the hepatic surface or near other organs are difficult to treat with this approach. The laparo- 
scopic approach tries to combine both to increase the proportion of treatable lesions and to minimize complications. This technique also allows for the identification of undetected liver tumors with the use of laparoscopic US [43]. This approach also allows to locate occult peritoneal or hepatic metastases not detected by conventional image techniques, enabling a more precise staging [37]. Local tumor recurrences in modern series appear to be low, and survival is similar as with other approaches $[44,45]$. Reductions in morbidity, cost and hospital stay as compared with open ablation have been reported [46]. Consensus documents recommend open approaches in patients undergoing resection with for unablatable disease, due to bulky disease or multiple clustered tumors in one area with ablation between one and four tumors in the remnant liver. The laparoscopic approach is recommended for tumors that are adherent to vulnerable structures. The percutaneous approach is preferred, as it is associated with less expense of hospital stay, morbidity and mortality [37]. Major complications are dependent on tumor size, electrode type, operator experience and number of ablation sessions. These complications are reported in $4-33 \%$ of patients. Major complications include intra-abdominal hemorrhage, tract seeding, liver abscess, intestinal perforation, portal thrombosis, biliary obstruction, pneumothorax, cholecystitis, cardiac arrest, and pulmonary embolism. Other, milder complications are ascites, biloma and celullites. One particular complication after thermal ablative therapies is post-ablation syndrome, which consists of low-grade fever, abdominal pain, malaise, myalgia, nausea, and vomiting. This complication is usually self-limiting in 7-10 days [6,47]. In observational and controlled studies, reported 5-year OS ranges from 27\% to 50\%, and 5-year recurrence free survival (RFS) ranges from $0 \%$ to $34 \%$, with a local recurrence rate of $11 \%$ to $37 \%[33,48]$.

Prognostic tools have been developed to define risk populations of patients and to help to improve patient selection. The modified clinical risk score (CRS) for ablation, which includes five items (node-positive primary-tumor, disease-free interval from primary tumor to liver metastases $<12$ months, number of tumors $>1$, any hepatic tumor $>3 \mathrm{~cm}$ and preRFA CEA > $30 \mathrm{ng} / \mathrm{mL}$ ) has shown to correlate with OS and local progression-free survival (LPFS) [36,39]. Other developed nomograms take into account other factors, such as the number of lesions, size of the biggest tumor, ablation margin $<10 \mathrm{~mm}$ and Ca 19.9 concentrations [49]. Interestingly, a nomogram was developed for unresectable patients receiving chemotherapy before RFA, which takes into account different validated prognostic factors, such as tumor size and number of lesions, but also response to chemotherapy, and it is designed for this specific clinical scenario, unlike other nomograms and scores [50]. The most important prognostic factor is the complete coverage of the targeted tumor by the ablation volume, with a sufficient ablation margin. Margins narrower than 5-10 $\mathrm{mm}$ are considered to be a poor prognostic factor for OS and LPFS [36,51-56]. Therefore, assessing correctly the margins achieved with the procedure is an aspect of capital importance. The effectiveness of the treatment is usually assessed with post-procedural imaging (US, CT, MR). The conventional approach consists in side-by-side juxtaposition of pre- and postinterventional CT scans and comparison by visual inspection, based on 2D images. Other different approaches have been proposed in order to improve outcomes and evaluation of the procedure. These approaches include the use of software to assess differences in size and attenuation of the lesions [57] or 3D software reconstructions of the ablated lesion to provide a quantifiable volumetric assessment of ablation completeness. This novel approach could challenge the traditional considered margins. A study has shown that ablations with a $100 \%$ circumscribed 3D safety margin of $3 \mathrm{~mm}$ or ablations with at least a $90 \%$ circumscribed 3D safety margin of $6 \mathrm{~mm}$ can be considered successful at the time of the intervention $[58,59]$. Other important prognostic factors are tumors $>3 \mathrm{~cm}$, multiple metastases, old age, node-positive primary, metachronous metastases [60-62], RAS mutations [51,56], right-sided colon cancer [63], prior hepatectomy [64], negative Ki-67 and positive caspase-3 adhered cells to the electrode [65] and absence of viable cells in a biopsy of the ablated lesions with a marginal biopsy showing a minimal margin of $>5 \mathrm{~mm}$ after the RFA procedure [66]. 
Multiple studies, systematic reviews and meta-analysis have been conducted for patients with LMCRC. The EORTC-CLOCC was a phase II randomized trial that compared systemic chemotherapy with FOLFOX (and from October 2005 in combination with Bevacizumab) with or without RFA in 119 patients diagnosed with unresectable LMCRC. A total of $25 \%$ of patients in the combination arm had solitary metastases, compared to $11.9 \%$ in the chemotherapy only group. There was a significant difference between arms in OS: 3-, 5- and 8-year OS were $56.9 \%, 43.1 \%$ and $35.9 \%$ respectively, in the combination arm and $55.2 \%, 30.3 \%$ and $8.9 \%$ respectively, in the chemotherapy only group (hazard ratio $(\mathrm{HR})=0.58,95 \%$ confidence interval $(\mathrm{CI})=0.38$ to $0.88, p=0.01$ ). However, $45.9 \%$ of patients in the RFA arm required resection in combination with ablation to obtain a complete tumor treatment, which may have cofounded the results. Median PFS was improved from 9.9 months ( $95 \% \mathrm{CI}=9.1$ to 12.9 months) to 16.8 months ( $95 \% \mathrm{CI}=11.0$ to 21.9 months), similar to that described in OS ( $\mathrm{HR}=0.57,95 \% \mathrm{CI}=0.38$ to $0.85, p=0.00)$. There were no differences in toxicity from the treatment [67]. Another phase II trial, the ARF2003, included 52 unresectable patients with LMCRC. Patients were treated with RFA (combined or not with surgery) 28 days after inclusion, and the primary endpoint of the trial was complete hepatic response at 3 months, with survival and safety as secondary endpoints. Neoadjuvant chemotherapy was allowed, and all patients received it before the procedure. Complete hepatic response at 3 months was $75 \%$. The 1 - and 5 -year OS were $94 \%$ and $43 \%$, respectively. LPFS at 1 and 3 years were $46 \%$ and 19\% [68]

Regarding the comparison between RFA and surgery, RFA shows higher recurrence rate and poorer long-term OS, PFS and disease-free survival (DFS) compared to surgery, even in solitary metastases $[60,69,70]$. Thirty-day mortality after the procedure is similar between interventions but complications are more frequent in patients undergoing surgery $[60,69,70]$. For patients treated with the combination of RFA and surgery (for unresectable tumors), no significant differences (compared to surgery for resectable tumors) were noted in regards to OS and DFS, although worse local progression free survival (LPFS) was shown [69]. However, when similar ablation and resection margins can be achieved, reports have shown no difference between these techniques [71]. A study comparing outcomes from patients treated with RFA ( \pm resection) from the CLOCC trial and only resection (from EPOC trial, a study of perioperative chemotherapy for LMCRC) was published. Although patients from CLOCC trial had a more advanced disease status compared with the resectable patients of the EPOC trial, local recurrence rates on a lesion basis were $6 \%$ and $5.5 \%$, respectively. The 3 y OS rates were also similar ( $88 \%$ vs. $90 \%$ ) [72]. The results from the COLLISION trial, a phase III trial currently recruiting, will compare surgical resection to RFA in CRC patients with lesions $<3 \mathrm{~cm}$ and are eagerly awaited, as they could answer whether RFA is non inferior in this population [34].

In recurrent colorectal liver metastases, the evidence is conflicting. Retrospective evidence by Dupré et al. suggest that surgery is associated with similar OS as RFA (median OS was not significantly different between the two groups, at 33.3 (95\% CI 28-54.7) months. One, three- and four-year OS were, respectively, $97 \%, 30.4 \%$ and $30.4 \%$ in the RFA group and $92.9 \%, 52.2 \%$ and $43.5 \%$ in the surgery group). PFS was significantly worse in the RFA group (4.3 months vs. 10.2 months) along with LPFS (5.4 months vs. 11.8 months) [73]. In one single-center retrospective study, RFA was chosen as the first-line treatment in recurrent colorectal liver metastases. Patients not amenable to RFA were offered surgery instead. Local recurrence in the site of the procedure was different between groups, favoring surgery ( $32 \%$ in the RFA group and $4 \%$ in the surgery group, $p<0.001$. This trend was also seen in time to progression. It was significantly shorter in patients primarily treated with RFA (203 vs. 416 days; $p=0.017$ ) However, no significant differences between RFA and surgery were noted in appearance of new metastases in the liver (50\% vs. $34 \%$ ) or extrahepatic ( $32 \%$ vs. $37 \%$ ). Of the liver-recurrent patients, $50 \%$ in the RFA group and $27 \%$ were candidates for reintervention (RFA or surgery). No differences in OS were noted between groups (3 y OS 67\% vs. 60\% $p=0.930$ ) [74]. Prospective evidence by Dijkstra et al., in contrast, found no difference between LPFS, distant-PFS or OS between RFA and surgery 
in patients with mostly single metastases ( $64.5 \%$ of patients) and with small lesions $<3 \mathrm{~cm}$ (84\% of patients). There were no difference in complications but significantly smaller hospital stay in patients treated with RFA [75].

\subsection{Microwave Ablation}

MWA generates frictional heat by creating electromagnetic radiation in the 900 to $2450 \mathrm{MHz}$ range from an antenna placed in the lesion to treat. As this technique is associated with lesser heat loss in the surrounding tissue, the antenna provides a broader field of active heating, up to $2 \mathrm{~cm}$ from the antenna, in contrast to RFA. This allows to treat larger lesions by using multiple antennas. Other advantages of this technique are a shorter procedure time and the absence of grounding pads, and this may be safer for the patient [76]. Indications and contraindications to this procedure are similar to RFA as are the complication rate and severity [47].

Evidence is conflicting regarding the efficacy of MWA, with less data published. Median OS in case series range from 24 months to 40 months. The reported 3-, 4- and 5-year OS varies between $35 \%$ and $79 \%, 35 \%$ and $58 \%$, and $17 \%$ and $32.9 \%$, respectively $[69,77]$. Factors associated with worse OS and local control are tumor size $(>3 \mathrm{~cm})$, tumor location (high-risk locations, such as near to a large vascular structure or diaphragm), number of lesions, elevated CEA levels prior to the procedure and the absence of response to chemotherapy before MWA $[77,78]$. One nomogram described previously also included patients treated with MWA and therefore, can be used in this population [49].

No trial has compared MWA in combination with chemotherapy vs. chemotherapy alone, but indirect observational evidence suggests greater survival with the combined approach [79]. One randomized clinical trial compared MWA to surgery in 30 patients with multiple $(<10)$, smaller than $8 \mathrm{~cm}$, resectable liver metastases. There were no differences in median OS (25 vs. 27 months) or median DFS (13.3 vs. 11.3 months), with fewer post-procedure complications [80]. This study has its limitations, as there is an absence of intention-to-treat analyses with $25 \%$ of the randomized patients not included in the final analyses. A retrospective observational study comparing MWA to surgery found no significant differences in OS and DFS, and a 2018 systematic review found similar oncologic outcomes to resection $[69,81]$. A combined approach with MWA + surgery in patients in whom surgery is considered insufficient to achieve free margins vs. surgery alone in patients that are candidates for surgery showed no significant differences in recurrence-free survival (RFS), OS and DFS between these groups, with $19 \%$ of postoperative complications in the combination arm [82].

Pooled analyses and meta-analyses suggest no significant difference between RFA and MWA in terms of complications, but some suggest benefit in terms of the lower local tumor progression (LTP) rate and improved DFS and OS [70,83-86]. In a retrospective review of 110 patients, authors found no evidence of differences in local tumor control between these techniques when stratified by margins, stressing the importance of adequate margins (superior to 5-10 mm). However, importantly, unlike RFA, the efficacy of MWA ablation was not affected by perivascular tumors [55]. In comparison with laparoscopic RFA, laparoscopic MWA appears to have better local control but without significant differences in OS or DFS [84]. However, due to the limitations of the studies analyzed, randomized controlled trials are necessary to compare these two techniques. Ablation of resectable lesions with MWA will be allowed in the COLLISION trial, described before. This will provide valuable information about the efficacy of MWA in resectable patients in direct comparison with surgery [34]. MWA has also shown to be the most cost-effective strategy, compared to RFA and surgery, with the lowest overall cost and the highest cumulative cost-effectiveness, although in the resectable scenario [87].

Table 3 shows representative retrospective studies of RFA and MWA. 
Table 3. Representative retrospective studies of RFA and MWA.

\begin{tabular}{|c|c|c|c|c|c|c|c|}
\hline Study & Year & $n$ & Treatment & $\begin{array}{l}\text { Indication of } \\
\text { Treatments }\end{array}$ & OS (Months) & $\begin{array}{l}\text { PFS/RFS } \\
\text { (Months) }\end{array}$ & Local Control \\
\hline $\begin{array}{l}\text { Abdalla } \\
\text { et al. [88] }\end{array}$ & 2004 & 468 & $\begin{array}{c}\text { Group 1: } \\
\text { Intraoperative RFA, } \\
\text { surgery } \pm \text { RFA } \\
\text { Group 2: CT }\end{array}$ & $\begin{array}{l}\text { RFA reserved for } \\
\text { patients not candidates } \\
\text { for surgery. CT: Not } \\
\text { candidates for RFA or } \\
\text { surgery }\end{array}$ & $\begin{array}{c}\text { S: 3-year } 73 \% p<0.05 \\
\text { S + RFA: 3-year } 43 \% \\
\text { RFA: 3-year 37\% }\end{array}$ & $\begin{array}{c}\text { S: Better than } \\
\text { RFA and RFA + } \\
\text { surgery } p<0.05\end{array}$ & $\begin{array}{c}\text { Liver recurrence } \\
\text { S: } 11 \% p<0.05 \\
\text { RFA + surgery: } 28 \% \\
p<0.05 \\
\text { RFA: } 84 \% p<0.05\end{array}$ \\
\hline $\begin{array}{l}\text { Kim et al. } \\
\text { [89] }\end{array}$ & 2011 & 505 & $\begin{array}{l}\text { Surgery, surgery + } \\
\text { RFA, RFA only (open } \\
\text { or percutaneous) }\end{array}$ & $\begin{array}{l}\text { RFA reserved for } \\
\text { patients not candidates } \\
\text { for surgery. }\end{array}$ & $\begin{array}{c}\text { S: 5-year: } 34.6 \% \\
\text { S + RFA: 5-year: } 22.9 \% \\
\text { RFA: 5-year: } 14.3 \%\end{array}$ & $\begin{array}{c}\text { S: 5-year DFS: } \\
16.2 \% \\
\text { S + RFA: 5-year } \\
\text { DFS: } 18.4 \% \\
\text { RFA: } 5 \text {-year DFS } \\
7 \% p<0.05\end{array}$ & NR \\
\hline $\begin{array}{l}\text { Schiffman } \\
\text { et al. [90] }\end{array}$ & 2010 & 140 & $\begin{array}{l}\text { Surgery, RFA only } \\
\text { (open) }\end{array}$ & $\begin{array}{c}\text { RFA reserved for } \\
\text { patients not candidates } \\
\text { for surgery. Solitary } \\
\text { metastases. }\end{array}$ & $\begin{array}{c}\text { S: } 112.7 \mathrm{~m} \\
\text { RFA: } 50.2 \mathrm{~m} p<0.05\end{array}$ & $\begin{array}{l}\text { S: } 52 \mathrm{~m} \\
\text { RFA: } 42 \mathrm{~m}\end{array}$ & $\begin{array}{c}\text { Local recurrence } \\
\text { S: } 12.6 \% \\
\text { RFA: } 35.6 \% p<0.05\end{array}$ \\
\hline $\begin{array}{l}\text { Tinguely } \\
\text { et al. [91] }\end{array}$ & 2020 & 727 & $\begin{array}{l}\text { Surgery, MWA only } \\
\text { (open, laparoscopic } \\
\text { and percutaneous) }\end{array}$ & $\begin{array}{l}\text { MWA reserved for } \\
\text { patients not candidates } \\
\text { for surgery with } \\
\text { lesions }<3 \mathrm{~cm}\end{array}$ & $\begin{array}{c}\text { WTPS S: } 54.5 \mathrm{~m} \\
\text { WTPS RFA: } 43.4 \mathrm{~m} \\
p<0.05 \\
\text { WPS S: } 54.7 \mathrm{~m} \\
\text { WPS MWA: } 48 \mathrm{~m}\end{array}$ & NR & NR \\
\hline $\begin{array}{c}\text { Shady et al. } \\
\text { [36] }\end{array}$ & 2016 & 165 & $\begin{array}{c}\text { RFA only } \\
\text { (percutaneous) }\end{array}$ & $\begin{array}{l}\text { RFA reserved for } \\
\text { patients not candidates } \\
\text { for surgery or } \\
\text { recurrence of previous } \\
\text { surgery }\end{array}$ & $\begin{array}{c}\mathrm{mOS} ; 36 \mathrm{~m} \\
\text { Patients without LP: } \\
65 \mathrm{~m} \\
\text { Patients locally } \\
\text { retreated after LP: } \\
51 \text { months } \\
\text { Patients not treated } \\
\text { after LP: } 22 \mathrm{~m} p<0.05\end{array}$ & NR & $\begin{array}{l}\text { mLTPFS: } 26 \mathrm{~m} \text {. Poor } \\
\text { prognosis: tumors }>3 \mathrm{~cm} \text {, } \\
\text { ablation margin }<5 \mathrm{~mm} \\
\quad p<0.05\end{array}$ \\
\hline $\begin{array}{l}\text { Shady et al. } \\
\text { [55] }\end{array}$ & 2018 & 154 & RFA only, MWA only, & $\begin{array}{l}\text { RFA reserved for } \\
\text { patients not candidates } \\
\text { for surgery }\end{array}$ & NR & NR & $\begin{array}{c}\text { 24-m LTPFS: RFA: } 66 \% \\
\text { 24-m LTPFS MWA: } 60 \% \\
\text { LTP < } 5 \text { mm AM: } 71 \% \\
p<0.05 \\
\text { LTP 5-10 mm AM: } 14.8 \% \\
\text { LTP } 10 \text { mm AM: } 0 \%\end{array}$ \\
\hline $\begin{array}{l}\text { Dijkstra } \\
\text { et al. [75] }\end{array}$ & 2021 & 136 & $\begin{array}{l}\text { RFA only, MWA only, } \\
\text { surgery }\end{array}$ & $\begin{array}{l}\text { Recurrent CLM. RFA } \\
\text { and MWA use at } \\
\text { discretion of a MDT }\end{array}$ & $\begin{array}{c}\text { S: } 49.4 \mathrm{~m} \\
\text { Ablative: } 54.4 \mathrm{~m}\end{array}$ & $\begin{array}{c}\text { Distant 3-year } \\
\text { PFS S: } 26.6 \% \\
\text { Distant 3-year } \\
\text { PFS ablative: } \\
24 \%\end{array}$ & $\begin{array}{c}\text { 1-year LTPFS S: } 96.1 \% \\
\text { 1-year LTPFS ablative: } \\
91.6 \%\end{array}$ \\
\hline
\end{tabular}

Abbreviations: AM—ablation margin, CLM—colorectal liver metastases, DFS—disease-free survival, LP—local progression, M-months, MDT—multidisciplinary team, mLTPFS—-median local tumor progression-free survival, mOS—median overall survival, $n$-number of patients, OS—overall survival, PFS—-progression-free survival, S—surgery, WPS — with propensity score matching, WTPS—without propensity score matching. Significant differences between groups are represented by significative $p$ values. $p$ values of not significant differences between arms are not shown.

\subsection{Cryoablation}

Cryoablation, in contrast with the techniques described above, consists in the infusion of argon within a lesion through a percutaneous probe, thus dropping the lesion tissue temperature to -40 degrees Celsius. Tissue necrosis occurs from -20 degrees Celsius, with a direct effect on the neoplastic cells by causing membrane damage and protein denaturalization, and with an indirect effect caused by the vasoconstriction of blood vessels and hypoxic injury. This procedure can be performed percutaneously, intraoperative or in conjunction to resection to achieve free margins, in what is known as edge cryotherapy [92]. The size of the treatment field depends on the configuration of the probe. There are some advantages to this procedure, as it causes lesser pain to the patient, and the treatment field can be delimited more easily with a post-procedure CT or real-time intraoperative US. However, there are important disadvantages, as the tissue adjacent to great vessels may not fall to a sufficient temperature to cause cell death, similar to a "reverse" heat-sink effect [93]. The lack of a coagulative effect on the surrounding tissue can also contribute to potential bleeding complications. Another important concern with the use of cryotherapy is the cryoshock phenomenon. The absence of a precise definition makes it difficult to establish an approximate incidence. Patients suffering from cryoshock have disseminated intravascular coagulation and multi-organ failure, similar to septic shock but without any microbiological isolates. A large multicenter survey estimated that it was responsible for $18 \%$ of peri- 
procedural deaths [94], but more recent series report a very low incidence $[92,95,96]$. The high rate of complications of earlier series and the fear of cryoshock led to this technique being displaced in favor of other ablative techniques [97].

A Cochrane systematic review was published to assess the role of cryotherapy for the treatment of liver metastases. Only randomized trials were included in the analyses. After review of the literature, only one randomized clinical trial was found [98]. This trial randomized 123 consecutive patients (82 patients with LMCRC) to cryosurgery versus conventional surgery. A high risk of bias is present, as there is no information provided to assess the sequence generation or allocation concealment [99]. The cryosurgery consisted of diverse procedures, including cryoresection using a self-constructed cryogenic clamp to freeze the desired incision line, and cryoablation. Mortality at 3, 5 and 10 years was $40 \%$, $56 \%$ and $81 \%$ in the cryotherapy group and $49 \%, 64 \%$ and $92 \%$ in the conventional surgery group, respectively. No significant differences were found. Reported adverse events were similar between groups (10\% and $20 \%$ ), except in the case of pain, which was worse in the cryotherapy group $[98,99]$.

Case series report diverse 1-, 3- and 5-year OS, ranging between $46 \%$ and $92 \%, 8 \%$ and $60 \%$, and $0 \%$ and $44 \%$, with major complication rates ranging from $1.5 \%$ to $66 \%$ and minor complication rates between $20 \%$ and $55 \%$. Edge cryotherapy case series report similar survival to R0 resection, but major complications compare unfavorably to major hepatectomy $[95-97,100]$.

Table 4 shows the main randomized clinical trials regarding RFA, MWA and cryoablation.

Table 4. Main clinical trials using RFA, MWA or cryoablation as experimental arm.

\begin{tabular}{|c|c|c|c|c|c|c|c|c|}
\hline Study & Type & Year & $n$ & Treatment & Complications & OS (Months) & $\begin{array}{c}\text { PFS } \\
\text { (Months) }\end{array}$ & Local Control \\
\hline $\begin{array}{c}\text { CLOCC } \\
\text { [67] }\end{array}$ & $\mathrm{RCT}$ & 2012 & 119 & $\begin{array}{l}\text { Local + systemic } \\
\text { Systemic only }\end{array}$ & $\begin{array}{l}\text { Total } \\
\text { percentage of } \\
\text { patients not } \\
\text { reported. }\end{array}$ & $\begin{array}{l}8 \text { years: } 35.9 \% \\
8 \text { years: } 8.9 \%\end{array}$ & $\begin{array}{c}16.8 \\
9.9\end{array}$ & $\begin{array}{c}\text { Hepatic progression: } \\
46.7 \% \\
\text { Hepatic progression: } \\
78 \%\end{array}$ \\
\hline $\begin{array}{c}\text { ARF2003 } \\
{[68]}\end{array}$ & $\begin{array}{l}\text { Phase } \\
\text { II }\end{array}$ & 2012 & 52 & $\mathrm{RFA} \pm$ surgery & $\begin{array}{c}\text { RFA: } 42.3 \% \\
\text { RFA + surgery: } \\
40.4 \%\end{array}$ & 5 years: $43.9 \%$ & 1 year: $27 \%$ & 1 y LPFS: $46 \%$ \\
\hline $\begin{array}{l}\text { Shibata } \\
\text { et al. [80] }\end{array}$ & $\mathrm{RCT}$ & 2000 & 30 & $\begin{array}{l}\text { MWA } \\
\text { Surgery }\end{array}$ & $\begin{array}{l}14.28 \% \\
12.5 \%\end{array}$ & $\begin{array}{l}27 \mathrm{~m} \\
25 \mathrm{~m}\end{array}$ & $\begin{array}{l}11.3 \text { (DFS) } \\
13.3 \text { (DFS) }\end{array}$ & Not reported \\
\hline $\begin{array}{l}\text { Korpan } \\
\text { et al. [98] }\end{array}$ & $\mathrm{RCT}$ & 1997 & 123 & $\begin{array}{l}\text { Cryosurgery } \\
\text { (including } \\
\text { cryoablation) } \\
\text { Conventional } \\
\text { surgery }\end{array}$ & $\begin{array}{l}10 \% \\
20 \%\end{array}$ & $\begin{array}{l}10 \text { years: } 81 \% \\
10 \text { years: } 92 \%\end{array}$ & NR & $\begin{array}{l}10 \text { years: } 14 \% \\
10 \text { years: } 5 \%\end{array}$ \\
\hline
\end{tabular}

Abbreviations: DFS—disease-free survival, LPFS—local progression-free survival, MWA—-microwave ablation, $n$-number of patients, NR - not reported, OS — overall survival, RCT—randomized controlled trial, RFA—radiofrequency ablation, Y—year. No significant differences between groups are noted; therefore, $p$ value is not shown.

\subsection{Other Ablative Therapies}

\subsubsection{Laser Interstitial Thermal Therapy (LITT)}

LITT involves the placement of laser fibers (usually neodymium-doped yttrium aluminum garnet (Nd-YAG)) in the lesion to treat, inducing electromagnetic heating by the conversion of light into heat and causing coagulation necrosis [101]. These laser fibers can be introduced percutaneously or by endoscopic ultrasound [102]. Conventional fibers allow zones of 1-2 cm to be ablated with this technique, as the surrounding tissue absorbs light and limits heat transferring [103]. Newer interstitial fibers with diffusing tips can provide larger ablation areas up to $50 \mathrm{~mm}$ [104]. To ablate larger volumes, multiple fibers need to be placed, but caution is advised, as the carbonization of the skin is a potential complication of high power ablation treatments [105]. This technique also allows to monitor temperature 
maps on the tissue in real time with CT or MR, due to the lack of metal and the small diameter of the applicators [106]. General anesthesia is not needed. This technique is not feasible in patients with more than 5 lesions and lesions greater than $5 \mathrm{~cm}$ in diameter [107].

Literature reviews suggest a local progression rate of $5.2 \%$ to $10 \%$ at 6 months of follow-up [47]. In a cohort with long-term follow up, mOS from the time of first LITT was 25 months. mOS in the patients treated with curative intent was 29 months vs. 21 months in patients treated with palliative intent. Significant prognostic factors in multivariate Cox analyses were the number and diameter of the biggest metastases, as well as the primary lymph node stage. Patients with one metastasis showed a mOS of 30 months, while patients with $\geq 4$ lesions had 18 months of mOS. In patients with tumors $<20 \mathrm{~mm}$, mOS was 36 months, while patients with $>40 \mathrm{~mm}$ metastases had an mOS of 21 months. mPFS was 13 months with no differences regarding the intention of the treatment. A stepwise backward hazard ratio model revealed the number of metastases and their diameters as significant prognostic factors. In patients with lesions $<20 \mathrm{~mm}, \mathrm{mPFS}$ was 21 months. In patients with metastases $>40 \mathrm{~mm}$, mPFS dropped to 10 months. Similarly, patients with up to 1 metastases had a mPFS of 18 months, while patients with more than 4 metastases had a mPFS of 10 months [108]. The major complication rate ranged from $0.1 \%$ to $3.5 \%$ with pleural effusion, subcapsular hematomas, abscess, pneumothorax, pleuritis, intrahepatic hemorrhage and biloma as the main major complications described in the literature [47,109].

LITT allows the use of finer needles than RFA or MWA, so endoscopic ultrasound (EUS) guidance has drawn some attention as a novel technique that would allow to ablate lesions at the left or caudate lobe of the liver since these locations are frequently hard to ablate percutaneously. A phase I trial was conducted, which included 3 patients with LMCRC, with no major complications reported. At 3 months post-procedure, MR showed an absence of enhancing in the treated lesions. No long-term results were reported. This study is the first to describe the feasibility of this procedure in ablating LMCRC endoscopically [102].

\subsubsection{High-Intensity Focused Ultrasound (HIFU)}

HIFU is based on the production of high-intensity ultrasound waves at a low frequency $(0.8-1.6 \mathrm{MHz})$ by a transducer outside of the body. The US waves are focused into a small region (with a range from $1 \times 1.5 \mathrm{~mm}$ to $10 \times 16 \mathrm{~mm}$ ). This raises the temperature of the affected tissue $>55$ degrees Celsius, causing thermocoagulation necrosis. At higher acoustic intensities, the generation of oscillating gas bubbles that accumulate heat due to mechanical friction with US waves can also cause tissue damage by cavitation. Cavitation is caused by mixed thermic and mechanic tissue damage caused by collapsing gas bubbles [110].

The key advantage of this form of ablation is that it is performed noninvasively, minimizing the risk of bleeding or unintentional organ injury. Nonetheless, if the lesions to be treated are located at the hepatic dome near the diaphragm, an artificial pleural effusion must be created to improve the sonographic window [111]. Other authors describe the removal of the ribs to improve the sonographic window and diminish the osteonecrosis risk, altering the non-invasive nature of this procedure [112]. There have been attempts to adapt this technique to the intra-operative setting, without compromising asepsis of the procedure [113]. The main disadvantage of this procedure is that each application of HIFU can only encompass a small volume of tissue, so sequential treatments are needed to cover larger volumes of tissue, resulting in long ablation and anesthesia times [114]. The most frequent HIFU complications are skin burns on the application site and osteonecrosis of the bones along the US pathway. Other potential complications, although irregularly reported, are fever and pleural effusion [112].

There are not published phase III trials of this technique for the treatment of colorectal liver metastases, although there are positive phase III trials in the symptomatic treatment of painful bone metastases and for the treatment of hepatocellular carcinoma (HCC), compared to the use of trans-arterial chemoembolization only (TACE) $[115,116]$. There are retrospective data from a study which included 43 colorectal patients, not candidates for 
resection, for whom HIFU was selected as the ablation technique. There are no reported data about why HIFU was the technique chosen. In this cohort, no complete responses (CR) by RECIST 1.1 criteria were seen, but an ORR of $39.5 \%$ of colon and $64.5 \%$ of rectum patients was reported. mOS was 12 months for both, and 1-year OS was $66.6 \%$ and $86.67 \%$, respectively. Adverse prognostic factors were ECOG $\geq 2$, longest lesion diameter $\geq 5 \mathrm{~cm}$, the presence of extrahepatic metastases and portal vein invasion [117]. Prospective data come from two small phase 1 trials. In the first one, 10 patients not candidates for surgery that specifically asked for HIFU treatment were treated. The rate of primary effectiveness (percentage of patients without progression of the treated lesions among the total) was $20 \%$, with $100 \%$ of minor complications, particularly osteonecrosis of the rib, and $20 \%$ of major periprocedural complications, leading to the death of a patient. No other outcomes were reported [111]. Another phase I trial, designed specifically for patients not candidates to resection or RFA by technical criteria and without extrahepatic disease was recently published in which 13 patients were included. ORR by mRECIST was $100 \%$, with $76.9 \%$ of $\mathrm{CR}$. The locorregional failure rate, defined as the appearance of new lesions surrounding or in the same hepatic segment, was $61.5 \%$. An additional HIFU treatment was feasible in all recurring patients, but the ORR was $89 \%$. mPFS was 9 months, with a 2-year PFS of $16.7 \%$. mOS was 25 months with a 2 -year OS of $77.8 \%$. A total of $84.6 \%$ of the patients received systemic therapy after HIPU, and chemotherapy could be resumed a week after the procedure. Adverse events (AE) occurred in $69.3 \%$ of patients with no grade 3-4 AEs. No osteonecrosis of the rib was noted [118].

\subsubsection{Irreversible Electroporation (IRE)}

Irreversible electroporation (IRE) uses short, powerful electric fields (70-90 pulses of high energy $1000-2500 \mathrm{~V} / \mathrm{cm}^{2}$ with $100 \mathrm{msec}$ of duration) to create membrane pores in tumor cells, causing membrane disruption and leading to cell apoptosis, not coagulative necrosis as RFA or MWA [119,120]. Proteins are not damaged, so the acellular component of the stroma is not affected by this technique [120]. A critical advantage of this technique is the avoidance of the "heat sink" effect described for RFA and MWA, as the short duration of pulses allows the tissue to cool and avoid thermal effects [121], and cell death is not dependent on coagulative necrosis. Some experiments have showed that under certain circumstances, thermal coagulation on the tissue is present with IRE [122], but this temperature increase is not considered to be detrimental to the surrounding connective tissue at the recommended settings. Nonetheless, placement of the electrodes $\leq 2 \mathrm{~mm}$ to large vascular structures is not recommended, and, if inevitable, the electrode placed should be the positive one, as it is the colder one. Metallic objects, such as stents, should also be avoided because they can cause alterations in the electric field distribution and could compromise the effectiveness of the procedure [123].

This treatment is currently only indicated for tumors not amenable for surgical resection or thermal ablation. This technique is most effective for tumors $\leq 3 \mathrm{~cm}$, with patients with more than four metastases being suboptimal candidates [124]. Its main application is in the treatment of central lesions with large vessels or bile ducts in proximity [125]. IRE can be performed during laparotomy or percutaneously, guided by CT or US. General anesthesia is needed, as a muscular relaxation on the patient is mandatory to avoid uncontrolled muscle contractions causes by the electric fields. Cardiac monitoring is also required, as ventricular arrythmias are a serious potential complication of this technique. It is important to note that modern devices are synchronized to the electrocardiogram (ECG) of the patient to deliver pulses in the refractory period of the cardiac contraction to avoid this complication. Other potential complications are hepatic abscesses, pneumothorax, bleeding, portal vein thrombosis and bile duct leakage or occlusion [124,126]. Needle tract seeding following IRE was also described [127]. In a systematic review of retrospective studies, the overall complication rate (OCR) was $16 \%$ with no major complications reported [124]. In a single-institution series of 85 IRE ablation procedures, major complications occurred in $7.1 \%$ of patients, while minor complications occurred in $18.8 \%$ [128]. 
In another study comparing RFA and IRE for the treatment of HCC, no differences were noted regarding the post-procedure complication rate, post-procedure hospital stay, or frequency of post-procedure ICU stay or length. The intervention time was longer in the IRE patients [129].

In regard to the treatment of liver metastases of colorectal origin, a phase II trial was recently published [130]. The COLDFIRE-II is a single-arm, multicenter study that included 51 patients with liver-only metastatic colorectal cancer, with at least one ${ }^{18} \mathrm{~F}-\mathrm{FDG}$ PET-avid lesion measuring $\leq 5 \mathrm{~cm}$ considered anatomically unsuitable for resection and in which thermal ablation was contraindicated, due to tumoral vicinity to a major bile duct, abutment of a single remaining major portal vein or hepatic vein and unreconstructable invasion of the free wall of the inferior vena cava. Patients did not receive adjuvant systemic therapy following IRE, but neoadjuvant treatment was allowed. Multimodal treatment for other liver tumors as concurrently thermal ablation or surgery was also allowed. The study met its primary endpoint with a 1-year local PFS of $68 \%$. Median distant PFS was 5.3 months, the liver being the most frequent site of first recurrence. Median extrahepatic PFS was 12.5 months. mOS from first IRE was 2.7 years. Eight patients underwent repeat treatment with IRE. Local tumor control in the repeated procedures was achieved in $74 \%$. The overall complication rate was $40 \%$. The most frequent grade $3-4$ AEs were de novo biliary obstruction, periprocedural arrythmias and portal vein thrombosis. A treatment-related death due to an infected biloma was reported [130]. Systematic reviews of retrospective series report a primary efficacy of the procedure within a range of $67-100 \%$ and secondary efficacy within 55-93\% [124]. In a study reporting long-term follow up of patients treated with IRE, complete ablation after first IRE was achieved in $66.7 \%$ of patients, and $95.8 \%$ after reintervention. No differences in OS were noted regarding tumor size (small vs. $\geq 2 \mathrm{~cm}$ ). The OS of the entire cohort was 26.5 months, with 1-, 3-, and 5-year OS of $79.1 \%, 25 \%$ and $8.3 \%$, respectively [131].

\subsubsection{Stereotactic Body Radiotherapy (SBRT)}

SBRT is defined as an external beam radiotherapy used to deliver a high dose of radiation very precisely to an extracranial target within the body, as a single dose or a small number of fractions [132]. It represents a non-thermal and non-invasive ablation technique. In order to achieve high-precision delivery, motion management techniques are needed in order to avoid unnecessary radiation of the surrounding tissue. The new approach of MR-guided adaptative therapy is a novel technique for delivering treatment, coupling MRguided acquisition of images before, during and after the delivery of treatment. This allows for better monitoring for in-treatment changes in position of the lesion to treat. Additionally, it allows for a better delimitation of tumors in the liver [133]. For liver metastases, fiducial placement is usually used to improve correct treatment delivery. In MR-guided SBRT, no fiducials are needed, avoiding an unnecessary invasive procedure [133]. Apart from the treated lesion, a margin of $5 \mathrm{~mm}$ of normal tissue is usually added. Different schemes and fractions are used, but typical dose schedules range from 3 to 8 fractions delivering 45-60 Gy for liver metastases [134]. CRC is considered radioresistant, but this resistance can be overcome by the high doses achieved with this technique [135].

Eligible lesions for SBRT must be below $5 \mathrm{~cm}$ in maximum diameter. SBRT, unlike thermal ablation therapies (specially RFA), can be used in lesions adjacent to great vessels, as no heat-sink effect is present, and lesions near other organs (subcapsular, periampullary) where colocation of an electrode is risky. However, caution must be taken in the planification of the treatment, as other tissues with different radiation sensitivity can be harmed during the delivery of the treatment, such as the GI tract [136]. Other reviewed techniques could be useful in this context (i.e., hydrodissection during thermal ablation, IRE, and radiation segmentectomy). Guidelines from ESMO and NCCN note that, as other ablative therapies, SBRT could represent a potentially curative treatment, alone or in combination with surgery to achieve no evidence of disease and represent an important option for patients not amenable to surgery or other forms of ablation $[5,11,19]$. 
SBRT can achieve a local control rate up to $90 \%$ at 24 months depending on size $[137,138]$. Results from two phase II trials were recently published. In an international trial, 99 patients (18.2\% of patients with CRC) with a controlled primary tumor and up to 5 metastatic lesions were randomized to systemic palliative therapy versus standard of care and SBRT of all metastatic lesions. This study showed benefit in the SBRT arm in terms of PFS and OS (6 months vs. 12 months and 28 months vs. 41 months, respectively). Adverse events grade $\geq 2$ were more common in the SBRT arm [139]. However, several limitations of this trial must be noted, as compared groups are very heterogeneous in primary histologies and metastases in different sites. No information is provided regarding the use and timing of systemic therapies. These limitations make the trial results difficult to interpret and extrapolate, as was noted by a multidisciplinary expert comment [140]. In the other published phase II trial, 42 patients not amenable for surgery or RFA with liver-limited disease, and with no more than 3 lesions with a diameter $<6 \mathrm{~cm}$, were included. Complete response was achieved in $22(43 \%)$ lesions, partial response in $17(32 \%)$, and stable disease in $9(17 \%)$. mPFS was 12 months and mOS was 29 months. No grade $\geq 3$ toxicity was found, but G2 hepatic toxicity was 78\%. Univariate analyses showed that OS was worse in lesions $>3 \mathrm{~cm}$ [141].

Data from a systematic review found that local control and PFS can be achieved, even in pretreated patients, and data from retrospective databases confirmed the benefit that can be achieved in patients for whom control of all metastatic disease can be achieved. However, relapses can be present in up to $31 \%$ of treated patients. Local control was $67 \%$ at one year, while the pooled two-year LC was 59.3\%. Pooled one- and two-year OS were $67.18 \%$ and $56.5 \%$, respectively. Median PFS and OS were 11.5 and 31.5 months. Correlation analyses found a significant correlation between dose and local control and OS, but with a poor linear correlation $[9,142]$. One retrospective study compared outcomes between patients who received MWA vs. patients who received SBRT in a tertiary care center. This study showed better freedom from local progression (FFLP) in patients receiving SBRT (1-year FFLP 91\% vs. $84 \%$ ), especially in those with lesions $>3 \mathrm{~cm}$ [143]. Another study comparing MWA to SBRT in patients included in AmCORE registry showed conflicting results. In this study, SBRT was associated with worse OS, even in patients with lesions $<3 \mathrm{~cm}$, (mOS median OS 53.0 months vs. 27.4 months) and worse LTP (29\% vs. $8.9 \%$ ), compared to thermal ablation. Patients treated with SBRT were older, with larger lesions and more extrahepatic disease [144]. Neither of these two studies explore the role of ablation margins and do not stratify results by this important prognostic factor. Other retrospective databases from international consortiums underscore the role of registries in standardizing the treatment of our patients, as the optimal regime has to be defined. These retrospective databases confirm the heterogeneity of the regimes used and suggest that the size of the treated lesions and dose administered could be considered prognostic factors $[145,146]$.

\section{Hepatic Arterially Directed Therapies}

Locoregional therapies administered through the hepatic artery for the treatment of LMCRC include chemoinfusion, chemoembolization and radioembolization. Hepatic malignancies receive $80 \%$ of their blood supply from the hepatic artery in contrast to the normal liver, which receives $80 \%$ of its blood supply from the portal vein and $20 \%$ from the hepatic artery [147]. Hepatic arterially directed therapies through the hepatic artery target the cells of LMCRC with relative sparing of normal liver parenchyma.

\subsection{Chemoinfusion}

Chemoinfusion (CI) or hepatic artery infusion is the delivery of chemotherapy (CT) directly into the hepatic artery that results in high exposure of the liver to the chemotherapeutic drug. CT can be delivered through catheters placed percutaneously into the hepatic artery or through pumps and catheters that are surgically implanted $[148,149]$. The most commonly used drug is floxuridine (FUDR), an antimetabolite of fluorouracil, because it has a high first pass clearance by the liver: it increases hepatic exposure and decreases 
systemic exposure. Irinotecan and oxaliplatin have been also used $[150,151]$. CI may present several adverse events, such as catheter malfunction, arterial occlusion, hepatic toxicity or biliary sclerosis [152,153].

CI was compared to systemic CT for first-line treatment for unresectable LMCRC. Several prospective clinical trials published in the late 1980s to early 1990s comparing CI with QT demonstrated superior response rates of $\mathrm{CI}$ therapy but did not show consistent improvements in OS [154-156]. Two meta-analyses confirmed these results $[157,158]$.

The improvements in the $\mathrm{CI}$ technique of pump placement, the methods of optimizing pump CT and the development of new therapies generated a new interest in CI, so new studies have explored the use of $\mathrm{CI}$ in conjunction with QT. A randomized trial compared treatment of LMCRC using CI FUDR, LV and dexamethasone to systemic CT (5-FU and $\mathrm{LV})$. mOS was 24.4 months for $\mathrm{CI}$ vs. 20 months for CT. The time to hepatic progression was 9.8 months for CI vs. 7.3 months for CT. However, the time to extrahepatic progression was 7.7 months for CI vs. 13.8 months with QT [159]. A study of 153 patients randomized to receive CI FUDR alone or CI FUDR and systemic 5-FU as first-line therapy demonstrated no difference in ORR (52.7\% vs. 50.6\%) and OS (18.0 vs. 19.1 months) [160].

Most institutions have already abandoned the use of $\mathrm{CI}$ alone, so diverse studies have tested the efficacy of $\mathrm{CI}$ with a combination of oxaliplatin and irinotecan. A phase I study with 49 patients with unresectable LMCRC treated with CI FUDR and dexamethasone and CT (oxaliplatin and irinotecan) demonstrated a high ORR (92\%) and a conversion to resection $(47 \%)$, with a mOS of 51 months [161]. A total of 87 patients received CI oxaliplatin with 5-FU and LV as second-line treatment of LMCRC, and $24 \%$ of patients underwent resection, with 5-year OS of 56\% [162]. A total of 28 patients with LMCRC received CI oxaliplatin followed by intravenous CT (5-FU and LV). The ORR was $64 \%$, and mOS was 27 months [163]. Recent studies demonstrated high response and conversion to resection rates, using combinations of modern systemic agents (Table 5) [164-167].

Table 5. Main trials using CI in unresectable LMCRC.

\begin{tabular}{|c|c|c|c|c|c|c|c|}
\hline \multicolumn{8}{|c|}{ Comparing CI to Systemic QT } \\
\hline Study & Type & Year & $n$ & Treatment & ORR (\%) & \multicolumn{2}{|c|}{ mOS (Months) } \\
\hline \multirow{2}{*}{ MSKCC [154] } & \multirow{2}{*}{$\mathrm{RCT}$} & \multirow{2}{*}{1987} & 48 & CI FUDR & 53 & \multicolumn{2}{|c|}{17} \\
\hline & & & 51 & IV FUDR & $21(p<0.05)$ & \multicolumn{2}{|c|}{12} \\
\hline \multirow{2}{*}{ Martin [155] } & \multirow{2}{*}{$\mathrm{RCT}$} & \multirow{2}{*}{1990} & 61 & HAI FUDR & 48 & \multirow{2}{*}{\multicolumn{2}{|c|}{$\begin{array}{l}12.6 \\
10.5\end{array}$}} \\
\hline & & & 76 & IV 5-FU & $21(p<0.05)$ & & \\
\hline \multirow{2}{*}{ Kerr [156] } & \multirow{2}{*}{$\mathrm{RCT}$} & \multirow{2}{*}{2003} & 145 & HAI 5-FU+LV & 22 & \multirow{2}{*}{\multicolumn{2}{|c|}{$\begin{array}{l}14.7 \\
14.8\end{array}$}} \\
\hline & & & 145 & IV 5-FU+LV & 19 & & \\
\hline \multirow{2}{*}{ CALGB [159] } & \multirow{2}{*}{$\mathrm{RCT}$} & \multirow{2}{*}{2006} & 68 & HAI FUDR+LV & 47 & \multirow{2}{*}{\multicolumn{2}{|c|}{$\begin{array}{c}24.4 \\
20(p<0.05)\end{array}$}} \\
\hline & & & 67 & IV 5-FU & $24(p<0.05)$ & & \\
\hline \multicolumn{8}{|c|}{ Comparing CI with Systemic QT } \\
\hline Study & Type & Year & $n$ & CI & IV QT & $\begin{array}{c}\text { ORR } \\
(\%)\end{array}$ & $\begin{array}{l}\text { CTR } \\
(\%)\end{array}$ \\
\hline $\begin{array}{l}\mathrm{D}^{\prime} \text { Angelica } \\
\text { [164] }\end{array}$ & Phase II & 2015 & 49 & FUDR & $\begin{array}{l}\text { Oxaliplatin/irinotecan/bevacizumab or } \\
\text { FOLFIRI/bevacizumab }\end{array}$ & 76 & 47 \\
\hline Levi [165] & Phase II & 2016 & 64 & $\begin{array}{c}\text { Irinotecan/ } \\
\text { oxaliplatin/5-FU }\end{array}$ & Cetuximab & 40.6 & 29.7 \\
\hline $\operatorname{Lim}[166]$ & $\begin{array}{l}\text { Multicenter } \\
\text { retrospective }\end{array}$ & 2017 & 61 & Oxaliplatin & $\begin{array}{l}\text { 5-FU/LV or 5-FU/Bev or } \\
\text { 5-FU/anti-EGFR }\end{array}$ & 21.3 & 16.4 \\
\hline Pak [167] & Phase II & 2018 & 64 & FUDR & $\begin{array}{l}\text { Oxaliplatin/irinotecan or } \\
\text { FOLFIRI/bevacizumab }\end{array}$ & 73 & 52 \\
\hline
\end{tabular}

Abbreviations: 5-FU—fluorouracil, Bev-bevacizumab, CI-chemoinfusion, CTR-conversion to resection, FUDR-floxuridine, IV QT-intravenous chemotherapy (systemic therapy), LV-leucovorin, mOS-median of overall survival, $n-$ number of patients, NR-not reported, ORR—objective responses rates, RCT—randomized controlled trial. 
$\mathrm{CI}$ as adjuvant treatment has demonstrated mixed results. Three studies showed increase in PFS and OS [168-170], but another study did not show any survival benefit [171]. In 2014, a Cochrane review of seven available randomized adjuvant CI studies showed no increase in OS [172].

A study followed 287 patients that underwent adjuvant CI with FUDR and systemic QT after resection of LMCRC, from 1991 onward. The patients were divided into two groups: those treated before 2003 and after. Results of this study showed greater 5- and 10 -year OS in those treated after 2003 , compared to before $78 \%$ vs. $56 \%$, and $61 \%$ vs. $40 \%$, respectively. These differences were thought to be secondary to new targeted therapies, more aggressive surgical treatment of recurrences, and better imaging [173].

Subsequent studies considered whether or not CI therapy was given with perioperative modern systemic therapy as a subgroup analysis to further delineate the contribution of modern QT [174]. A study of 21-year analysis of perioperative CI included 2368 patients with resected LMCRC from 1992 to 2012. The results showed prolonged 5-year OS for patients receiving CI therapy, compared to those treated without CI (52.9\% vs. $37.9 \%)$ [175]. For those that received preoperative modern systemic QT, the median OS in the CI arm and the no-CI arm were 77 and 45 months, respectively. For those that did not receive preoperative modern systemic QT, $\mathrm{mOS}$ rates in the QT arm and the no QT arm were 55 and 43 months, respectively [176]. Despite the increased effectiveness of modern systemic QT, there is still a benefit in OS with the addition of CI therapy to systemic therapy in the perioperative setting.

The place of CI in the therapeutic armamentarium for $\mathrm{mCRC}$ is not clear. NCCN guidelines consider $\mathrm{CI}$ as an option of treatment in resectable and unresectable LMCRC, but it should be considered selectively and only at institutions with experience in this procedure. It is an acceptable first-line option in the United States for unresectable LMCRC and a treatment option in the adjuvant treatment, but it remains infrequently used $[177,178]$. However, ESMO guidelines do not recommend CI [5]. Spanish guidelines regarding the management of LMCRC do not mention CI [12].

\subsection{Chemoembolization}

Transarterial chemoembolization (TACE) adds arterial obstruction to the delivery of a chemotherapeutic drug. The most commonly employed chemoembolization protocol combines the delivery of chemotherapeutic drugs emulsified in ethiodized oil with particulate embolization. The ethiodized oil/chemotherapeutic mixture lodges distally within the hepatic arterioles and portal venules, trapping the chemotherapeutic drug in the tumor microvasculature. The embolization following the delivery of the ethiodized oil/chemotherapeutic mixture leads to stasis and increased contact time within the tumor, which increases local drug delivery, reducing systemic exposure $[179,180]$. This combined treatment results in the retention of the chemotherapeutic drug in the tumor cells for several weeks, while they clear from normal hepatocytes within seven days [181].

Chemotherapeutic agents, such as doxorubicin or irinotecan, are ionically bound to particles of various sizes. These include hydrogels, microspheres and polymer implants. The most extensively studied are non-biodegradable polyvinyl alcohol (PVA) microspheres (beads) (DC-Bead, Biocompatibles, West Conshohocken, PA, U.S.A.). The beads are joined sulfonic acid containing a moiety producing a charge that permits the interaction and binding with oppositely charged chemotherapeutic agents [182]. Beads of varying diameter (70-900 microns) are loaded with chemotherapeutic agents, and they are delivered in a lobar, segmental or superselective arterial distribution.

Drugs eluting beads loaded with irinotecan (DEBIRI) is a useful alternative for TACE in LMCRC $[183,184]$. DEBIRI loco-regional activity and pharmacologic profile differs from doxorubicin. Therefore, irinotecan is preferred in LMCRC, and doxorubicin is mostly used in HCC. [185]. The irinotecan is released from DC-Beads inside LMCRC, and DC-Beads occlude liver arterial vessels. However, the ischemic effect alone is not enough to justify the extent of the tumor response observed, so the irinotecan effect is required. The use of DC- 
Beads alone results in a lower tumor response than what is observed with different doses of DEBIRI, confirming the importance of both embolization and drug activity [186]. Another result of embolization-induced ischemia is the decrease in liver $\mathrm{pH}$ that activates irinotecan.

The most common complication following TACE is postembolization syndrome that is caused by the release of cytokines and subsequent inflammation by tissue ischemia [187]. This syndrome appears in $30-80 \%$ of patients, with right upper quadrant pain, nausea, vomiting and fever. Additional complications include liver failure, hepatic abscess formation, biloma, biliary ischemia or ductal injury [188].

A study with 121 patients with LMCRC treated with TACE (mitomycin C, doxorubicin and cisplatin with ethiozied oil) described that $41 \%$ and $57 \%$ of patients had stable disease and disease progression, respectively [189]. Median time to liver progression was 5 months and mOS following the first TACE was 9 months. These results are similar to other older series, that reported mOS of 8-14 months from the time of first TACE $[190,191]$.

Table 6 shows the most important results of studies that analyzed the paper of chemoembolization as the first-line treatment of LMCRC. One study evaluated the role of the addition of conventional TACE (cisplatin + 5-FU) to systemic QT in first-line treatment of unresectable LMCRC [192]. It was a retrospective 4-arm study of 154 patients with KRAS wild-type LMCRC comparing QT (FOLFOX/FOLFIRI) + / - cetuximab vs. QT (FOLFOX/FOLFIRI) + / - cetuximab plus TACE. mOS was different between the study arms, as 5-years PFS. A phase 2 trial tried to evaluate in 70 patients the benefit of the addition of DEBIRI to systemic therapy in the first-line treatment of unresectable LMCRC: FOLFOX with or without bevacizumab vs. FOLFOX with or without bevacizumab plus DEBIRI [193]. However, the patients in the two arms were not similar at the baseline evaluation (patients from DEBIRI intervention arm had worse performance status and more extrahepatic disease). There were no differences in response to treatment between the study arms at 2, 4 and 6 months using RECIST 1.1, but there was a significantly better response at 2 months in the DEBIRI arm (98\% vs. $82 \%)$.

Table 6. Results of studies evaluating benefits of addition of DEBIRI to systemic therapy in first-line treatment of LMCRC.

\begin{tabular}{|c|c|c|c|c|c|c|}
\hline \multicolumn{7}{|c|}{ Conventional TACE [192] } \\
\hline \multicolumn{2}{|l|}{ Study Arm } & \multicolumn{2}{|c|}{ mOS (Months) } & 5-Year PFS (\%) & $\begin{array}{l}\text { Conversion to } \\
\text { Resection (\%) }\end{array}$ & ORR (\%) \\
\hline \multicolumn{2}{|l|}{ QT } & \multicolumn{2}{|c|}{17.5} & 2.5 & 7.0 & 11.6 \\
\hline \multicolumn{2}{|l|}{$\mathrm{QT}+\mathrm{TACE}$} & \multicolumn{2}{|c|}{28.4} & 22.3 & 30.8 & 46.2 \\
\hline \multicolumn{2}{|l|}{ QT + cetuximab } & \multicolumn{2}{|c|}{18.9} & 7.6 & 10.5 & 34.2 \\
\hline \multicolumn{2}{|c|}{$\mathrm{QT}+$ cetuximab + TACE } & \multicolumn{2}{|c|}{30.3} & 20.3 & 32.4 & 44.1 \\
\hline \multicolumn{7}{|c|}{ DEBIRI [193] } \\
\hline Study Arm & $n$ & $\begin{array}{c}\text { mOS } \\
\text { (Months) }\end{array}$ & $\begin{array}{c}\text { mPFS } \\
\text { (Months) }\end{array}$ & $\begin{array}{c}\text { RECIST } \\
\text { Response Rate (\%) }\end{array}$ & $\begin{array}{c}\text { Choi Response } \\
\text { Rate }(\%)\end{array}$ & $\begin{array}{c}\text { Toxicity } \\
\text { (\% Grade 3, 4) }\end{array}$ \\
\hline mFOLFOX + Bev & 30 & NR & 15 & $\begin{array}{l}2 \mathrm{m:}: 89 \% \\
4 \mathrm{m:}: 95 \% \\
6 \mathrm{m:} 89 \%\end{array}$ & 82 & 46 \\
\hline mFOLFOX + Bev + DEBIRI & 40 & NR & $12(p=0.18)$ & $\begin{array}{l}2 \mathrm{~m}: 88 \% \\
4 \mathrm{~m}: 97 \% \\
6 \mathrm{~m}: 92 \% \\
\text { (All NS) }\end{array}$ & $98(p=0.01)$ & 54 \\
\hline
\end{tabular}

Abbreviations: Bev—-bevacizumab, DEBIRI—drug eluting beads loaded with irinotecan, FOLFOX—5-fluoruracil, leucovorin, oxaliplatin, mFOLFOX - modified FOLFOX, mPFS—median of progression-free survival, mOS-median of overall survival, QT-chemotherapy, RECIST—response evaluation criteria in solid tumor, TACE—-transarterial chemoembolization.

Several studies analyzed the benefit of DEBIRI as second or later line treatment in patients with unresectable LMCRC (Table 7). A phase 2 trial that studied DEBIRI in 82 patients reported that mOS was 25 months, mPFS was 8 months and ORR was $78 \%$ 
3 months after DEBIRI [194]. Another phase 2 study analyzed 40 patients treated with DEBIRI plus capecitabine. mOS was 8 months and PFS was 4 months [195]. A phase 3 trial with 74 patients compared DEBIRI to FOLFIRI. OS and PFS was longer in the DEBIRI arm (22 months vs. 15 months, 7 months vs. 4 months, respectively). Similarly, ORR and time to hepatic progression were better in the DEBIRI arm ( $68.6 \%$ vs. $20 \%, 7$ months vs. 4 months). An evaluation of KRAS demonstrated that within the DEBIRI treatment arm, those with wild-type KRAS had better OS than those with mutated KRAS (26 months vs. 14 months) [196].

Table 7. Results of studies evaluating benefits of addition of DEBIRI to systemic therapy in second-line or later treatment of LMCRC [193].

\begin{tabular}{cccccccc}
\hline Study & Study Type & $\begin{array}{c}\text { Study Arm or } \\
\text { Arms }\end{array}$ & $\boldsymbol{n}$ & $\begin{array}{c}\text { mOS } \\
\text { (Months) }\end{array}$ & $\begin{array}{c}\text { mPFS } \\
\text { (Months) }\end{array}$ & $\begin{array}{c}\text { ORR (\%) } \\
\text { (\% Grade 3, 4) }\end{array}$ \\
\hline Aliberti [194] & SA & DEBIRI & 82 & 25 & 8 & NR & 25 \\
\hline Di Noia [195] & SA & $\begin{array}{c}\text { DEBIRI + } \\
\text { capecitabine }\end{array}$ & 40 & 8 & 4 & 17.5 & 20 \\
\hline Fiorentini [196] & RCT & FOLFIRI & 38 & & 4 & $\begin{array}{c}\text { Noxicity } \\
44 \text { vs. 4 } \\
\text { Mucositis: } \\
20 \text { vs. 1 }\end{array}$ \\
\hline
\end{tabular}

Abbreviations: DEBIRI-drug eluting beads loaded with irinotecan, FOLFOX-5-fluoruracil, leucovorin, oxaliplatin, FOLFIRI-5fluoruracil, leucovorin, irinotecan, mPFS—-median of progression-free survival, mOS—median of overall survival.

These studies suggest a benefit in terms of OS and PFS in the second-line setting, although the strength of evidence is low, owing to the small sample size. Treatment with DEBIRI may provide benefits to patients with liver predominant metastases whose disease has progressed during first-line systemic therapy. NCCN guidelines do not realize specific recommendations for DEBIRI. The TACE treatment is not described in the ESMO guidelines [5]. Spanish guidelines consider that DEBIRI is indicated as a third-line treatment when QT has failed in some non-resectable LMCRC and could provide an opportunity for some patients who need downstaging prior to surgery [12].

\subsection{Radioembolization}

Radioembolization (RE) or selectivity internal radiotherapy uses Yttrium-90. Yttrium90 is a radioactive beta emitter (maximum energy $2.27 \mathrm{MeV}$, mean range of $2.5 \mathrm{~mm}$ in liver tissue and half-life of $64.8 \mathrm{~h}$ ) embedded in resin (SIRSpheres, SIRTEX) or glass microspheres (Theraspheres, MDS Nordion) for delivery of high dose radiation to the tumor with reduced radiation exposure to the normal liver parenchyma [197,198].

The RE procedure consists of a catheterization of the hepatic artery through a femoral access to deliver Yttrium-90 microspheres to the hepatic parenchyma. These particles occlude the smallest capillaries, leaving the majority of the microspheres within the tumor, whereby they emit radiation therapy. The particles are radioactive for a period of 14 days but most of the radiation is delivered over five days. SIRSpheres and Theraspheres are used interchangeably, but SIRSpheres (20 to $40 \mu \mathrm{m}$ ) are approved for LMCRC and Theraspheres for hepatocellular carcinoma [199].

The RE process is realized in at least two parts. In the first session, a mapping portion is made. A Technetium-99 macro-aggregates albumin SPECT (single photon emission computed tomography) during which particles mimicking the Ytrrium-90 microspheres determine the percentage of lung shunting, which may occur with the RE procedure. If greater than $20 \%$ lung shunting occurs, the patient is not eligible for RE. The Yttrium-90 dose may be modified based on the percentage of lung shunting. Additionally, during this procedure, occlusion of the gastroduodenal artery may be realized to prevent retrograde flow of the microspheres, which can make gastric and duodenal ulcers [200]. The second procedure is the administration of the Yttrium-90 microspheres, which may be performed 
in a whole liver approach or sequential lobar treatments. The advantage of sequential treatments is to observe the effect of first RE and to assure that a sufficient contralateral liver reserve exists.

One important adverse event of RE is radiation-induced liver disease (RILD). The Yttrium-90 microspheres preferentially flow to the tumors due to the hepatic arterydominant blood supply for about $80 \%$ of liver tumors. The distribution of microspheres was confirmed in pathological studies [198]. RILD is a constellation of icteric ascites, hepatomegaly, and mild elevation to transaminases relative to bilirubin, which is markedly elevated. Patients who have been treated with QT prior to RE have higher risk for RILD [201]. Other risks of RE are constitutional symptoms, abdominal pain or gastric/duodenal ulcer.

There are not comparative studies studying if RE with Yttrium-90 is useful in patients with resectable LMCRC [202]. Several clinical trials have showed potential benefit for combining Yttrium-90 with intravenous fluoropyrimidine-based QT in patients with LMCRC $[203,204]$. RE with Ytrium-90 significantly improved PFS (4.5 months vs. 2.1 months, $p=0.03)$ and liver PFS (5.5 months vs. 2.1 months) but differences of OS were not significant (7.3 months and 10.0 months, $p=0.80$ ) [204]. The efficacy of combined therapy with Ytrrium-90 plus systemic QT over systemic QT alone as first-line treatment in patients with unresectable LMCRC was studied in three parallel phase III trials (SIRFLOX, FOXFIRE and FOXFIRE-Global) [205-207]. The three trials had very similar eligibility criteria and had a combined enrollment of 1103 patients who were randomly assigned to FOLFOX (+/ - targeted therapy) or FOLFOX (+/ - targeted therapy) plus Ytrrium-90 concurrent with cycle 1 or 2 .

Only the results of SIRFLOX study were fully published, and the others were included in abstract presentations. There is a pooled analysis of these three clinical trials in different publications [208-212]. A total of 549 patients were treated with QT alone and 554 were treated with QT plus Yttrium-90, at a median follow-up of 43 months. There was a higher ORR with combined therapy (72\% vs. 63\%) but there were no differences to mOS (22.6 months vs. 23.3 months) or mPFS (11 months vs. 10.3 months) [208]. There was significantly longer liver disease control in the Y90 group by 8 months $(20$ months for Y90 vs. 12 months for QT) in the SIRFLOX trial. Table 8 shows the most relevant results. Combined therapy had more grade 3 or 4 adverse events, especially hematologic toxicity. There were 11 treatment-related deaths: 8 were in the QT plus Ytrrium-90 group and 3 were attributed to RILD.

Table 8. Results of study evaluating benefits of addition of RE with Yttrium-90 to systemic therapy in first-line treatment of LMCRC [208].

\begin{tabular}{cccccc}
\hline Study Arm & $\boldsymbol{n}$ & mOS (Months) & mPFS (Months) & ORR (\%) & Toxicity (\% Grade 3, 4, 5) \\
\hline mFOLFOX & 549 & 23.3 & 10.3 & 63 & OR 1.42, 95\% CI: 1.09 to $1.85, p=0.089$ \\
\hline FOLFOX + RE & 554 & $22.6(p=0.061)$ & $11.3(p=\mathrm{NS})$ & $72(p=0.0012)$ & \\
\hline
\end{tabular}

Abbreviations: CI-confidence interval, FOLFOX-5-fluoruracil, leucovorin, oxaliplatin, mFOLFOX-modified FOLFOX, mPFS-median of progression-free survival, mOS—median of overall survival, OR—odds ratio, ORR—overall response rate, RE-radioembolization with Yttrium-90.

There are results of subgroup analyses of FOXFIRE, SIRFLOX and FOXFIRE-global. There were no OS differences between the treatment arms based on the KRAS mutation status [210]. OS was significantly greater in the QT plus Yttrium-90 in those with rightsided tumors (22 months vs. 26 months), but not left-sided tumors (24.6 months vs. 26.6 months) [211]. Similar results with respect to tumor localization were demonstrated when only the SIRFLOX and FOXFIRE-Global trials were combined [212].

Patients with LMCRC who have failed multiple systemic QT regimens may benefit from RE with Yttrium-90 [213-220]. A systematic review of 20 studies comprising 979 patients found that rates of complete radiologic response, partial response, and stable disease were $0 \%(0-6), 31 \%(0-73)$, and $40.5 \%$ (17-78), respectively [221]. The median time to intrahepatic disease progression was 9 months, mPFS was 4.9 months, and the mOS 
was 12 months. Acute toxicity developed in 11 to 100 percent (median 41 percent), most of which was mild. Only one small phase 3 clinical trial evaluated systemic QT alone (5-FU) and systemic QT (5-FU) plus RE with Ytrrium-90 [204]. There were differences in mPFS (2.1 months vs. 5.5 months), but mOS was similar in the two arms (7.3 months vs. 10 months). Recently, it has become known the results of the EPOCH trial [222], which was a phase 3 trial that demonstrated the effectiveness of the addition of RE to second-line chemotherapy. mPFS was 7.2 months in the control group, mPFS was 8.0 months in the RE group and the HR of PFS was 0.69 (95\% CI, 0.54 to 0.88 ; 1 -sided $p=0.0013)$. So it reflects a $31 \%$ protection against progression in $Y 90$ group. The median hepatic progression-free survival was 9.1 months in the RE group and 7.2 months in the control groups, and the HR was 0.59 (95\% CI, 0.46 to 0.77 ; 1-sided $p<0.0001$. mOS was 15.2 months in the RE group and 14.3 months in the control group. A significant benefit with the addition of RE was observed for patients with tumors with a KRAS mutation, left-side primary tumors, a tumor burden of $10-25 \%$, three or fewer lesions, the addition of a biologic agent and no detectable extrahepatic lesions.

It was investigated if there are several factors that could improve OS and liver PFS in patients treated with Y90. Kurilova et al. proposed a normogram that can predict OS in patients treated with $Y 90$ and pretreated with other treatments. This normogram includes six pre-Y90 treatment parameters: number of extrahepatic disease sites, carcinoembryonic antigen (CEA), albumin, alanine aminotransferase (ALT) level, tumor differentiation level and SUVmax of the two largest tumor diameters. Baseline SUVmax was the single significant predictor of liver PFS [223].

It is not easy to know how to incorporate RE with Yttrium-90 in the treatment of patients with LMCRC. The Radioembolization Brachytherapy Oncology Consortium (RBOC) suggests that RE with Yttrium-90 be limited to patients with unresectable LMCRCdominant tumor burden and a life expectancy over 3 months [213]. RBOC defends that an absolute contraindication to Yttrium-90 is a pretreatment Technetium-99 macro-aggregated albumin SPECT with $\geq 30$ Gy radiation exposure to the lung or flow to the gastrointestinal tract that cannot be corrected by catheter techniques. Other relative contraindications would be a limited hepatic reserve, irreversibly elevated serum bilirubin levels, a compromised portal vein, and prior radiotherapy involving the liver [224].

NCCN guidelines for mCRC consider RE with Ytrrium-90 as an option of treatment in highly selected patients, with resistant/refractory QT and predominant LMCRC which are not optimally resectable. The ESMO guidelines state that RE with Yttrium-90 can prolong PFS in patients with LMCRC failing the available QT [5]. The Spanish guidelines about LMCRC also propose that RE with Yttrium-90 is a chance of treatment when all available treatments fail. In addition, the Spanish guidelines think that RE with Yttrium-90 may be useful as a neoadjuvant treatment when R0 resection of LMCRC is difficult but the volume, outflow, inflow and biliary drainage of hepatic parenchyma is adequate [12].

\subsection{Other Hepatic Arterially Directed Therapies}

Bland embolization uses inert particles of several sizes and composition to obstruct tumor microvasculature, so it leads to tumor infarction. Bland embolization is effective in the treatment of hepatocellular carcinoma and liver metastases of neuroendocrine tumors, but it is not used for LMCRC [225].

\section{Emerging Technologies and Future Directions}

\subsection{Emerging Technologies}

As we have reviewed previously, an adequate targeting and the tumor and its margins is very important, as it is one of the most important prognostic factors. This targeting is highly dependent on the skill and experience of the operator. Needle navigation systems as well as ablation planning software are limited to viewing these datasets on 2D monitor screens. Emerging technologies in software allow 3D reconstructions that show promising results [226]. Taking a step further is the development and adaptation of virtual reality 
and augmented reality. This allows to stereoscopically view 3D datasets in actual threedimensional space, resulting in improved spatial understanding as well as procedure execution and safety, especially for inexperienced operators [227,228].

Although improvements in navigation will allow to precisely target the tumor, many of the ablative techniques discussed below do not allow to monitor changes in the treated tissue, and the evaluation of the ablated zone has to be done post-procedurally. Understanding and predicting the expected ablation zone for a single device is complex and involves interactions among the settings chosen by the operator, tissue density, tissue hydration, and local heat sinks, as discussed earlier [229]. In this regard, ablation planning software is an emerging technology that will help to provide better care to our patients [230].

Electrochemotherapy results from the combination of IRE with concomitant administration of chemotherapeutic drugs. Bleomycin is the agent used in the main trials published with this technique. Encouraging results are found with complete responses ranging within $55-85 \%$ with no serious adverse events [231-233]. Further studies are needed before applying electrochemotherapy in routine clinical practice.

Y90 radiation segmentectomy for LMCRC could be an option of treatment in selected patients. Padia et al. treated 36 patients who were not candidates for surgical resection or thermal ablation with LM (11 patients had LMCRC) by Y90 radiation segmentectomy; ORR was $92 \%$ (28\% partial response, $64 \%$ stable disease) and adverse events were low, without hepatic-related toxicity [234]. Kurilova et al. treated 10 patients with $\leq 3 \mathrm{LM}$ and limited treatment options. Y90 radiation segmentectomy can provide a 2-year local tumor control rate of $83 \%$ [235].

\subsection{Liver Transplantation in $C R C$}

The International Hepato-Pancreato-Biliary Association commissioned an international multidisciplinary group of experts to develop consensus guidelines, named the Liver Transplantation for Colorectal liver Metastases 2021 (LT-CoMet 21) working group, and this guideline was published recently. This guideline provides initial standardization of terms and proposes a therapeutic algorithm in a very novel oncology field as the transplant oncology. The selection of patients is crucial, as patients candidates for transplant must have non-resectable disease limited to the liver with favorable molecular prognosis markers (patients with V600 BRAF mutant CRC are excluded, due to their poor prognosis, while high microsatellite instability and deficient DNA mismatch repair are also excluded, but due to the notable results of immunotherapy in this population and concerns about the high allograft rejection rate associated with the administration of immunotherapy after solid organ transplantation). Adequate response to systemic therapy must be documented for at least 6 months over an interval of at least 1 year from the diagnosis of non-resectable colorectal liver metastases, ongoing at the time that the transplant is planned. In accordance with the ethical principle of utility, which incorporates beneficence and non-maleficence, this stringent patient selection process aims to identify patients with non-resectable colorectal liver metastases who would derive the most survival benefit from liver transplantation. Nonetheless, the inclusion of patients with malignant indications in transplantation list will cause tension to the principles of utility and justice, which is recognized by theLT-CoMet 21 working group [236].

Previous clinical trials in liver transplantation in LMCRC are the SECA I and SECA II trials, which showed promising results. In SECA I trial, 21 unresectable patients without signs of extrahepatic disease and a minimum of 6 weeks of chemotherapy treatment were included. No adjuvant chemotherapy was administered after the transplantation. The Kaplan-Meier estimate of 5-year OS was $60 \%$. Risk factors for death were carcinoembryonic antigen (CEA) $>80 \mathrm{mg} / \mathrm{L}$, progressive disease on chemotherapy, size of largest lesion $>5.5 \mathrm{~cm}$, and less than 2 years from resection of the primary tumor to transplantation. [237]. In the SECA II trial, with the stricter selection criteria and patients with significantly better prognostic factors than patients in SECA-I, the OS was improved to $83 \%$. Disease-free survival rates at 1,2 , and 3 years were $53 \%, 44 \%$, and $35 \%$, respectively. 
Overall survival rates from time of relapse at 1,2, and 4 years were $100 \%, 73 \%$, and $73 \%$, respectively. Regarding prognostic factors, the Fong Clinical Risk Score of 1 to 2 at the time of diagnosis resulted in longer disease-free survival than a score of 3 to 4 [238].

\section{Role of Biomarkers}

RAS mutations are probably the most studied genetic alterations influencing prognosis in patients with CRC. Mutations in the RAS family of proto-oncogenes (KRAS, NRAS, HRAS) are present in $30-45 \%$ of patients with colorectal cancers. These mutations cause a constitutive activation of the MAPK pathway, leading to resistance to treatment with EGFR antibodies.

RAS mutations affecting prognosis have been better defined in the resectable population, but efforts were made recently to characterize their effect in the ablation setting. As we have discussed earlier, RAS mutations in codons 12, 1361 and 146 and NRAS mutations in codons 12,13 and 61 have shown to be a negative prognostic factor of recurrence $[56,62,210]$. The interaction between RAS mutations and the margin of resection was also studied. Calandri et al. showed that achieving minimal ablation margins $>10 \mathrm{~mm}$ in mutant RAS tumors provides similar 3-year LTPFS as achieving $\leq 10 \mathrm{~mm}$ ablation margins in wild-type RAS tumors [51]. Shady et al. showed that mutant RAS tumors carry a risk of progression 15.6-fold higher when compared with wild-type RAS tumors ablated with ablation margins of $\geq 6 \mathrm{~mm}$ [56]. Although the RAS mutational status is not considered a contraindication to image-guided ablation, some authors recommend that RAS-mutated patients be considered candidates for resection only if adequate margins can be obtained (3D minimal ablation margins of $\geq 5 \mathrm{~mm}$ and $\geq 10 \mathrm{~mm}$ are desirable) [239].

BRAF, a protein kinase in the mitogen-activated protein kinase (MAPK) signaling pathway, is another important prognostic factor in CRC. BRAF V600E mutation are identified in $5-8 \%$ of patients, with especially poor prognosis with a median survival of only 12 months with chemotherapy alone [240]. Patients with CRC with BRAF V600E mutations rarely have metastases limited to the liver, and those who undergo liver resection (1-6.1\%) often develop disease recurrence [241]. To our knowledge, no study has addressed the role of BRAF V600E mutations in population treated with local ablation therapies or with liver-directed therapies.

Prognostic relevance of microsatellite instability (MSI) with deficient DNA mis- match repair (dMMR) is well established in early-stage tumors but its role in the metastatic setting is still under debate [242]. The promising results of first-line immunotherapy as shown by the KEYNOTE-177 trial with long-term disease control and response rate $(43.8 \%)$, higher than the chemotherapy arm, encourage the use of immunotherapy in the neoadjuvant setting [243]. However, published studies have focused on the neoadjuvant setting but in early stages and locally advanced cancers. The NICHE trial showed 100\% pathological response in $\mathrm{dMMR}$ and $27 \%$ in pMMR in early-stage CRC when using neoadjuvant ipilimumab and nivolumab [244]. Toripalimab, an anti PD-1 inhibitor, also showed 88\% complete responses in this setting [245]. However, concerns in the use of immunotherapy in the conversion therapy scenario were raised as progressive disease, as the best response, was present in $29.4 \%$ of patients in the immunotherapy group in contrast to $12.4 \%$ in the chemotherapy arm. Ongoing trials are exploring the combination of the anti-PD1 antibodies nivolumab and pembrolizumab with SIRT and TACE (NCT03380130, NCT03033446, NCT02837029, NCT03099564, and NCT03143270) and with radiotherapy or ablation (NCT02437071).

\section{Discussion}

The treatment of LMCRC is a clear example of advances in oncology that illustrates a change in a classic oncology idea (local therapy being used for local disease and systemic therapy being used in patients with systemic disease). LMCRC represent systemic disease, but the use of local therapies, such as surgical resection or ablation for patients with resectable LMCRC, may be a curative treatment [4]. Systemic therapy is the conventional treatment in patients with unresectable LMCRC. The benefit of non-surgical local treat- 
ments in patients with limited disease naturally raises the possibility that liver-directed regional therapies may provide benefit in patients with more extensive LMCRC.

Compared to chemotherapy alone, the addition of a multidisciplinary approach with local and loco-regional treatments improves outcomes in candidates for a more radical therapy. However, we must take into consideration that this subset of patients represents a group with an intrinsically better prognosis than the patients who are not candidates for intensive therapy and are only candidates for chemotherapy. Guidelines from ESMO, for example, consider that one of the first steps in the evaluation of a metastatic patient is to categorize it into a "never resectable" or "potentially resectable" group that will guide the therapies that the patient will receive $[5,19]$. The Figure 1 shows our suggestion of the algorithm treatment in unresectable LMCRC.

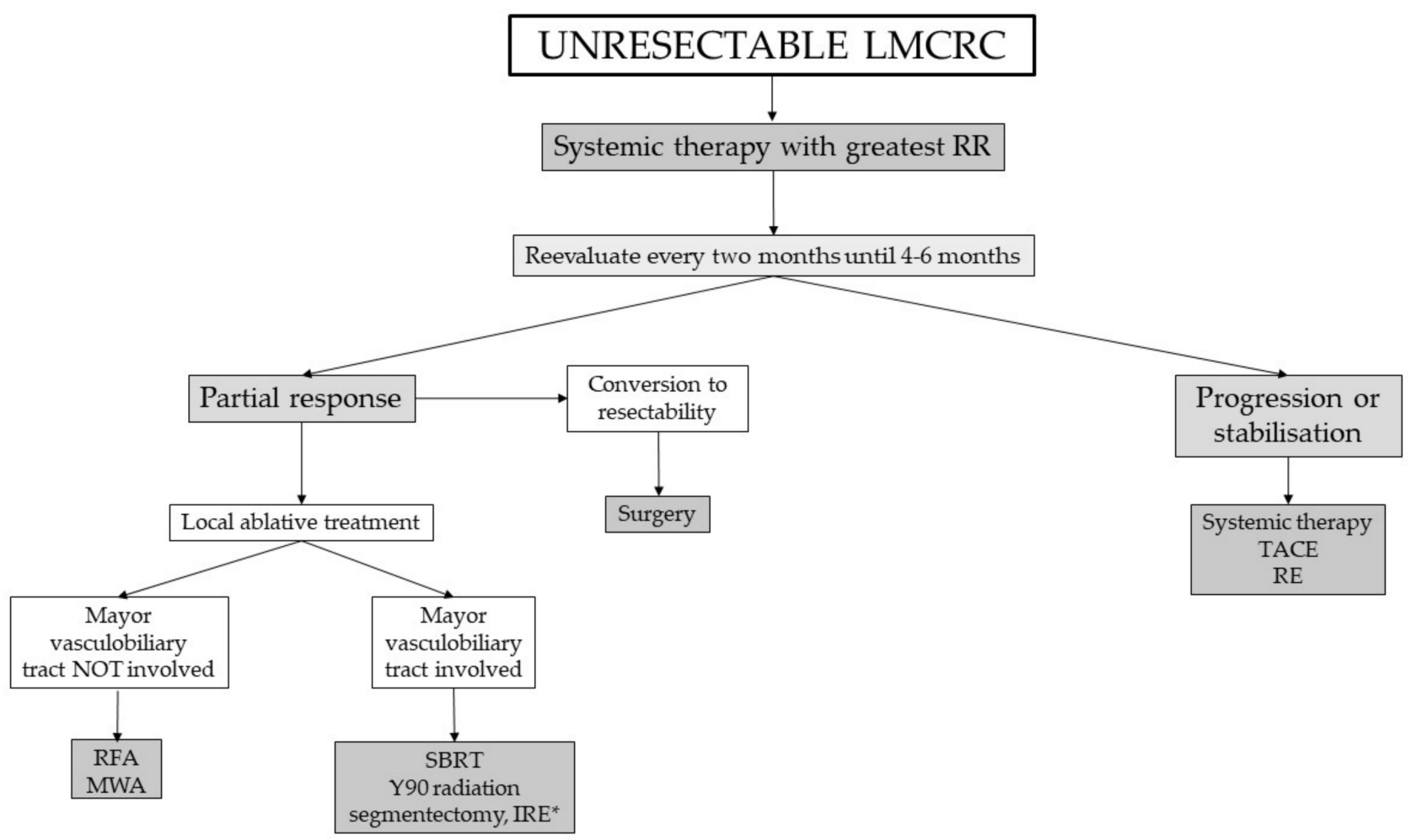

Figure 1. Algorithm treatment of LMCRC. Adapted from [5,19]. Abbreviations: IRE-irreversible electroporation, MWA-microwave ablation, SBRT—stereotactic body radiotherapy, TACE—transarterial chemoembolization, REradioembolization, RFA—radiofrequency ablation. * Y 90 radiation segmentectomy is indicated for tumors near major bile ducts or vascular structures.

Results reported with diverse LAT are difficult to compare to those reported for surgery, giving the inherent selection bias present in these series. The lack of randomized, prospective data of local ablative therapies is reflected in the consensus guidelines from different societies. All guidelines share the consideration that for a resectable patient, the gold standard treatment is surgery, and while LAT is traditionally reserved for patients with medical, technical or personal contraindications to surgery, this notion is being challenged in recent guidelines, as LAT can provide survival and local control rates similar to those of surgery in well-selected patients. No technique is preferred, as there is little evidence comparing different treatments, and the decision for using a certain technique is often related to the expertise of the treating team or operator. Different meta-analyses and systematic reviews have contributed to more robust evidence compared to isolated prospective series, but still the evidence is considered to be weak, and data from randomized, phase III trial are needed. Therefore, the COLLISION trial results are awaited, as they will shed some light on the best treatment for resectable patients. 
Regarding loco-regional treatments, the heterogeneity of the studies makes it difficult to interpret and compare the results between them. Many of these studies have a limited number of patients or are conducted at single institutions. Several studies that use one non-surgical treatment present diverse inclusion criteria, use different definitions, apply diverse techniques and local or systemic treatment, or evaluate the response to treatment in a different way. There are treatments that are not used in some places; for example, CI is used in European countries in an exceptional way, but it is frequent in United States. All this generates the impossibility of having robust results, and there are many questions in medical oncology that do not have an answer today, including the following: Which ablative therapy is better? Which embolization treatment is more useful? Is DEBIRI better than RE with Yttrium-90? It is necessary to conduct powerful clinical trials that try to respond to these clinical questions, although this may not be practical, given the complexities in non-surgical clinical treatments. Clinicians should discuss the non-surgical treatment with patients, taking into account patient preferences and the uncertainty of the evidence.

The selection of patients who could benefit from non-surgical local treatments is an interesting challenge in oncology. A small group of patients with LMCRC are candidates for these therapies. The majority of patients with LMCRC have some disease outside the liver, such as of the lung or peritoneum. The pattern of progression in patients with LMCRC is variable and not easy to predict, so clinical studies are necessary to identify patients with good prognosis. Other relevant consideration is the age of the patients. This raises the question of whether elderly patients could benefit from non-surgical treatment of LMCRC. Life expectancy is increasing in Western society, and many patients of LMCRC are diagnosed at an advanced age [246].

The advances in the treatment of LMCRC show the importance of working in a multidisciplinary way. The patients with LMCRC should be evaluated by a team composed of medical oncologists, surgical oncologists, radiation oncologists and interventional radiologists. This requires that all specialists speak in a similar way; in other words, the definition of unresectable, resectable and possible or potential resectable patient with LMCRC have to be similar, and every specialist has to know every non-surgical therapy, their indications and their effectiveness.

\section{Conclusions}

The management of LMCRC is becoming more aggressive and complex. New nonsurgical treatment of LMCRC complements systemic therapy by providing an opportunity for the local control of hepatic spread. Actual evidence supports non-surgical treatment in LMCRC, but it can be useful to maximize disease control and survival in selected patients. Although a multidisciplinary approach is recommended, it is necessary to establish standard practices for non-surgical treatment in LMCRC.

Author Contributions: J.T.-J., J.E.-V., R.F.-M. and A.C. contributed substantially for conceptualization, methodology, validation, investigation and writing. Supervision: R.F.-M. and A.C. All authors have read and agreed to the published version of the manuscript.

Funding: This research received no external funding.

Acknowledgments: The authors wish to thank the patients who participated and are currently participating in the studies mentioned and their families.

Conflicts of Interest: The authors declare no conflict of interest.

\section{Abbreviations}

$\begin{array}{ll}\text { 5-FU } & \text { 5-fluorouracil } \\ \text { AE } & \text { Adverse events } \\ \text { Bev } & \text { Bevacizumab }\end{array}$




\begin{tabular}{|c|c|}
\hline CI & Confidence interval \\
\hline CI & Chemoinfusion \\
\hline CRC & Colorectal cancer \\
\hline CR & Complete response \\
\hline CRS & Clinical risk score \\
\hline CT & Computer tomography \\
\hline CTR & Conversion to resection \\
\hline $\mathrm{D}$ & Dimension \\
\hline DEBIRI & Drug eluting beads loaded with Irinotecan \\
\hline DFS & Disease-free survival \\
\hline dMMR & Mismatch-repair deficient \\
\hline ECG & Electrocardiogram \\
\hline EGFR & Epidermal growth factor receptor \\
\hline ESMO & European Society of Medical Oncology \\
\hline FFLP & Freedom from local progression \\
\hline FOLFIRI & 5-fluorouracil, leucovorin, irinotecan \\
\hline FOLFOX & 5-fluorouracil, leucovorin, oxaliplatin \\
\hline FOLFOXIRI & 5-fluouracil, leucovorin, oxaliplatin, irinotecan \\
\hline FUDR & Floxuridine \\
\hline $\mathrm{HCC}$ & Hepatocellular carcinoma \\
\hline HR & Hazard ratio \\
\hline IL-2 & Interleukin 2 \\
\hline IRE & Irreversible electroporation \\
\hline HIFU & High-intensity focused ultrasound \\
\hline LAT & Local ablative therapies \\
\hline LMCRC & Liver metastases of colorectal cancer \\
\hline LPFS & Local progression-free survival \\
\hline LT-CoMet 21 & Liver Transplantation for Colorectal liver Metastases 2021 \\
\hline LTP & Local tumor progression \\
\hline LV & Leucovorin \\
\hline $\mathrm{mCRC}$ & Metastatic colorectal cancer \\
\hline MDT & Multidisciplinary team \\
\hline mOS & Median overall survival \\
\hline mPFS & Median progression-free survival \\
\hline MR & Magnetic resonance \\
\hline MSI & Microsatellite instability \\
\hline MWA & Microwave ablation \\
\hline $\mathrm{NCCN}$ & National Comprehensive Cancer Network \\
\hline NR & Not reported \\
\hline OR & Odds ratio \\
\hline ORR & Overall response rate \\
\hline OS & Overall survival \\
\hline PFS & Progression-free survival \\
\hline PVA & Polyvinyl alcohol \\
\hline QT & Chemotherapy \\
\hline RBOC & Radioembolization Brachytherapy Oncology Consortium \\
\hline RCT & Randomized controlled trial \\
\hline RE & Radioembolization \\
\hline RECIST & Response evaluation criteria in solid tumors \\
\hline RFA & Radiofrequency ablation \\
\hline RFS & Recurrence-free survival \\
\hline RILD & Radiation-induced liver disease \\
\hline SBRT & Stereotactic body radiotherapy \\
\hline SPRECT & Single photon emission computed tomography \\
\hline TAVE & Transarterial chemoembolization \\
\hline US & Ultrasound \\
\hline VEGF & Vascular endothelial growth factor \\
\hline
\end{tabular}




\section{References}

1. Keum, N.; Giovannucci, E. Global Burden of Colorectal Cancer: Emerging Trends, Risk Factors and Prevention Strategies. Nat. Rev. Gastroenterol. Hepatol. 2019, 16, 713-732. [CrossRef]

2. Rawla, P.; Sunkara, T.; Barsouk, A. Epidemiology of Colorectal Cancer: Incidence, Mortality, Survival, and Risk Factors. Prz. Gastroenterol. 2019, 14, 89-103. [CrossRef] [PubMed]

3. Sung, H.; Ferlay, J.; Siegel, R.L.; Laversanne, M.; Soerjomataram, I.; Jemal, A.; Bray, F. Global Cancer Statistics 2020: GLOBOCAN Estimates of Incidence and Mortality Worldwide for 36 Cancers in 185 Countries. CA A Cancer J. Clin. 2021, 71, 209-249. [CrossRef] [PubMed]

4. Kow, A.W.C. Hepatic Metastasis from Colorectal Cancer. J. Gastrointest. Oncol. 2019, 10, 1274-1298. [CrossRef]

5. Van Cutsem, E.; Cervantes, A.; Adam, R.; Sobrero, A.; Van Krieken, J.H.; Aderka, D.; Aranda Aguilar, E.; Bardelli, A.; Benson, A.; Bodoky, G.; et al. ESMO Consensus Guidelines for the Management of Patients with Metastatic Colorectal Cancer. Ann. Oncol. 2016, 27, 1386-1422. [CrossRef]

6. Nosher, J.L.; Ahmed, I.; Patel, A.N.; Gendel, V.; Murillo, P.G.; Moss, R.; Jabbour, S.K. Non-Operative Therapies for Colorectal Liver Metastases. J. Gastrointest. Oncol. 2015, 6, 224-240. [CrossRef]

7. Modest, D.P.; Pant, S.; Sartore-Bianchi, A. Treatment Sequencing in Metastatic Colorectal Cancer. Eur. J. Cancer 2019, 109, 70-83. [CrossRef]

8. de la Peña, C.; Gonzalez, M.F.; González, C.; Salazar, J.M.; Cruz, B. Stereotactic Body Radiation Therapy for Liver Metastases: Clinical Outcomes and Literature Review. Rep. Pract. Oncol. Radiother. 2020, 25, 637-642. [CrossRef] [PubMed]

9. Petrelli, F.; Comito, T.; Barni, S.; Pancera, G.; Scorsetti, M.; Ghidini, A. Stereotactic Body Radiotherapy for Colorectal Cancer Liver Metastases: A Systematic Review. Radiother. Oncol. 2018, 129, 427-434. [CrossRef]

10. Pawlik, T.M.; Choti, M.A. Surgical Therapy for Colorectal Metastases to the Liver. J. Gastrointest. Surg. 2007, 11, 1057-1077. [CrossRef]

11. National Comprehensive Cancer Network Colon Cancer. Version 2.2021. Available online: https://www.nccn.org/professionals/ physician_gls/pdf/colon.pdf (accessed on 26 July 2021).

12. Vera, R.; González-Flores, E.; Rubio, C.; Urbano, J.; Valero Camps, M.; Ciampi-Dopazo, J.J.; Orcajo Rincón, J.; Morillo Macías, V.; Gomez Braco, M.A.; Suarez-Artacho, G. Multidisciplinary Management of Liver Metastases in Patients with Colorectal Cancer: A Consensus of SEOM, AEC, SEOR, SERVEI, and SEMNIM. Clin. Transl. Oncol. 2020, 22, 647-662. [CrossRef] [PubMed]

13. Folprecht, G.; Grothey, A.; Alberts, S.; Raab, H.-R.; Köhne, C.-H. Neoadjuvant Treatment of Unresectable Colorectal Liver Metastases: Correlation between Tumour Response and Resection Rates. Ann. Oncol. 2005, 16, 1311-1319. [CrossRef] [PubMed]

14. Adam, R.; De Gramont, A.; Figueras, J.; Guthrie, A.; Kokudo, N.; Kunstlinger, F.; Loyer, E.; Poston, G.; Rougier, P.; Rubbia-Brandt, L.; et al. The Oncosurgery Approach to Managing Liver Metastases from Colorectal Cancer: A Multidisciplinary International Consensus. Oncologist 2012, 17, 1225-1239. [CrossRef]

15. Robinson, S.M.; Wilson, C.H.; Burt, A.D.; Manas, D.M.; White, S.A. Chemotherapy-Associated Liver Injury in Patients with Colorectal Liver Metastases: A Systematic Review and Meta-Analysis. Ann. Surg. Oncol. 2012, 19, 4287-4299. [CrossRef]

16. Hubert, C.; Sempoux, C.; Horsmans, Y.; Rahier, J.; Humblet, Y.; Machiels, J.-P.; Ceratti, A.; Canon, J.-L.; Gigot, J.-F. Nodular Regenerative Hyperplasia: A Deleterious Consequence of Chemotherapy for Colorectal Liver Metastases? Liver Int. 2007, 27, 938-943. [CrossRef] [PubMed]

17. Rubbia-Brandt, L.; Audard, V.; Sartoretti, P.; Roth, A.D.; Brezault, C.; Le Charpentier, M.; Dousset, B.; Morel, P.; Soubrane, O.; Chaussade, S.; et al. Severe Hepatic Sinusoidal Obstruction Associated with Oxaliplatin-Based Chemotherapy in Patients with Metastatic Colorectal Cancer. Ann. Oncol. 2004, 15, 460-466. [CrossRef]

18. Chun, Y.S. Association of Computed Tomography Morphologic Criteria With Pathologic Response and Survival in Patients Treated With Bevacizumab for Colorectal Liver Metastases. JAMA 2009, 302, 2338. [CrossRef]

19. Yoshino, T.; Arnold, D.; Taniguchi, H.; Pentheroudakis, G.; Yamazaki, K.; Xu, R.-H.; Kim, T.W.; Ismail, F.; Tan, I.B.; Yeh, K.-H.; et al. Pan-Asian Adapted ESMO Consensus Guidelines for the Management of Patients with Metastatic Colorectal Cancer: A JSMO-ESMO Initiative Endorsed by CSCO, KACO, MOS, SSO and TOS. Ann. Oncol. 2018, 29, 44-70. [CrossRef]

20. Xu, Q.; Xu, A.T.; Zhu, M.M.; Tong, J.L.; Xu, X.T.; Ran, Z.H. Predictive and Prognostic Roles of BRAF Mutation in Patients with Metastatic Colorectal Cancer Treated with Anti-Epidermal Growth Factor Receptor Monoclonal Antibodies: A Meta-Analysis: Predictive and Prognostic Roles of BRAF. J. Dig. Dis. 2013, 14, 409-416. [CrossRef]

21. Raghav, K.; Loree, J.M.; Morris, J.S.; Overman, M.J.; Yu, R.; Meric-Bernstam, F.; Menter, D.; Korphaisarn, K.; Kee, B.; Muranyi, A.; et al. Validation of HER2 Amplification as a Predictive Biomarker for Anti-Epidermal Growth Factor Receptor Antibody Therapy in Metastatic Colorectal Cancer. JCO Precis. Oncol. 2019, 1-13. [CrossRef]

22. Holch, J.W.; Ricard, I.; Stintzing, S.; Modest, D.P.; Heinemann, V. The Relevance of Primary Tumour Location in Patients with Metastatic Colorectal Cancer: A Meta-Analysis of First-Line Clinical Trials. Eur. J. Cancer 2017, 70, 87-98. [CrossRef]

23. Ye, L.-C.; Liu, T.-S.; Ren, L.; Wei, Y.; Zhu, D.-X.; Zai, S.-Y.; Ye, Q.-H.; Yu, Y.; Xu, B.; Qin, X.-Y.; et al. Randomized Controlled Trial of Cetuximab Plus Chemotherapy for Patients With KRAS Wild-Type Unresectable Colorectal Liver-Limited Metastases. JCO 2013, 31, 1931-1938. [CrossRef] [PubMed]

24. Carrato, A.; Abad, A.; Massuti, B.; Grávalos, C.; Escudero, P.; Longo-Muñoz, F.; Manzano, J.-L.; Gómez, A.; Safont, M.J.; Gallego, J.; et al. First-Line Panitumumab plus FOLFOX4 or FOLFIRI in Colorectal Cancer with Multiple or Unresectable Liver Metastases: A Randomised, Phase II Trial (PLANET-TTD). Eur. J. Cancer 2017, 81, 191-202. [CrossRef] 
25. Folprecht, G.; Gruenberger, T.; Bechstein, W.O.; Raab, H.-R.; Lordick, F.; Hartmann, J.T.; Lang, H.; Frilling, A.; Stoehlmacher, J.; Weitz, J.; et al. Tumour Response and Secondary Resectability of Colorectal Liver Metastases Following Neoadjuvant Chemotherapy with Cetuximab: The CELIM Randomised Phase 2 Trial. Lancet Oncol. 2010, 11, 38-47. [CrossRef]

26. Masi, G.; Loupakis, F.; Salvatore, L.; Fornaro, L.; Cremolini, C.; Cupini, S.; Ciarlo, A.; Del Monte, F.; Cortesi, E.; Amoroso, D.; et al. Bevacizumab with FOLFOXIRI (Irinotecan, Oxaliplatin, Fluorouracil, and Folinate) as First-Line Treatment for Metastatic Colorectal Cancer: A Phase 2 Trial. Lancet Oncol. 2010, 11, 845-852. [CrossRef]

27. Wong, R.; Cunningham, D.; Barbachano, Y.; Saffery, C.; Valle, J.; Hickish, T.; Mudan, S.; Brown, G.; Khan, A.; Wotherspoon, A.; et al. A Multicentre Study of Capecitabine, Oxaliplatin plus Bevacizumab as Perioperative Treatment of Patients with Poor-Risk Colorectal Liver-Only Metastases Not Selected for Upfront Resection. Ann. Oncol. 2011, 22, 2042-2048. [CrossRef]

28. Gruenberger, T.; Bridgewater, J.; Chau, I.; García Alfonso, P.; Rivoire, M.; Mudan, S.; Lasserre, S.; Hermann, F.; Waterkamp, D.; Adam, R. Bevacizumab plus MFOLFOX-6 or FOLFOXIRI in Patients with Initially Unresectable Liver Metastases from Colorectal Cancer: The OLIVIA Multinational Randomised Phase II Trial. Ann. Oncol. 2015, 26, 702-708. [CrossRef]

29. Modest, D.P.; Martens, U.M.; Riera-Knorrenschild, J.; Greeve, J.; Florschütz, A.; Wessendorf, S.; Ettrich, T.; Kanzler, S.; Nörenberg, D.; Ricke, J.; et al. FOLFOXIRI Plus Panitumumab As First-Line Treatment of RAS Wild-Type Metastatic Colorectal Cancer: The Randomized, Open-Label, Phase II VOLFI Study (AIO KRK0109). JCO 2019, 37, 3401-3411. [CrossRef] [PubMed]

30. Palussière, J.; Catena, V.; Buy, X. Percutaneous Thermal Ablation of Lung Tumors-Radiofrequency, Microwave and Cryotherapy: Where Are We Going? Diagn. Interv. Imaging 2017, 98, 619-625. [CrossRef]

31. Weiser, M.R.; Jarnagin, W.R.; Saltz, L.B. Colorectal Cancer Patients with Oligometastatic Liver Disease: What Is the Optimal Approach? Oncology 2013, 27, 1074-1078.

32. Belinson, S.; Chopra, R.; Yang, Y.; Shankaran, V.; Aronson, N. Local Hepatic Therapies for Metastases to the Liver From Unresectable Colorectal Cancer; AHRQ Comparative Effectiveness Reviews; Agency for Healthcare Research and Quality (US): Rockville, MD, USA, 2012

33. Cirocchi, R.; Trastulli, S.; Boselli, C.; Montedori, A.; Cavaliere, D.; Parisi, A.; Noya, G.; Abraha, I. Radiofrequency Ablation in the Treatment of Liver Metastases from Colorectal Cancer. Cochrane Database Syst. Rev. 2012. [CrossRef]

34. Puijk, R.S.; Ruarus, A.H.; Vroomen, L.G.P.H.; van Tilborg, A.A.J.M.; Scheffer, H.J.; Nielsen, K.; de Jong, M.C.; de Vries, J.J.J.; Zonderhuis, B.M.; COLLISION Trial Group; et al. Colorectal Liver Metastases: Surgery versus Thermal Ablation (COLLISION)— A Phase III Single-Blind Prospective Randomized Controlled Trial. BMC Cancer 2018, 18, 821. [CrossRef]

35. Solbiati, L.; Ahmed, M.; Cova, L.; Ierace, T.; Brioschi, M.; Goldberg, S.N. Small Liver Colorectal Metastases Treated with Percutaneous Radiofrequency Ablation: Local Response Rate and Long-Term Survival with Up to 10-Year Follow-Up. Radiology 2012, 265, 958-968. [CrossRef] [PubMed]

36. Shady, W.; Petre, E.N.; Gonen, M.; Erinjeri, J.P.; Brown, K.T.; Covey, A.M.; Alago, W.; Durack, J.C.; Maybody, M.; Brody, L.A.; et al. Percutaneous Radiofrequency Ablation of Colorectal Cancer Liver Metastases: Factors Affecting Outcomes-A 10-Year Experience at a Single Center. Radiology 2016, 278, 601-611. [CrossRef] [PubMed]

37. Gillams, A.; Goldberg, N.; Ahmed, M.; Bale, R.; Breen, D.; Callstrom, M.; Chen, M.H.; Choi, B.I.; de Baere, T.; Dupuy, D.; et al. Thermal Ablation of Colorectal Liver Metastases: A Position Paper by an International Panel of Ablation Experts, the Interventional Oncology sans Frontières Meeting 2013. Eur. Radiol. 2015, 25, 3438-3454. [CrossRef] [PubMed]

38. Livraghi, T.; Solbiati, L.; Meloni, F.; Ierace, T.; Goldberg, S.N.; Gazelle, G.S. Percutaneous Radiofrequency Ablation of Liver Metastases in Potential Candidates for Resection: The "Test-of-Time Approach". Cancer 2003, 97, 3027-3035. [CrossRef]

39. Sofocleous, C.T.; Petre, E.N.; Gonen, M.; Brown, K.T.; Solomon, S.B.; Covey, A.M.; Alago, W.; Brody, L.A.; Thornton, R.H.; D'Angelica, M.; et al. CT-Guided Radiofrequency Ablation as a Salvage Treatment of Colorectal Cancer Hepatic Metastases Developing after Hepatectomy. J. Vasc. Interv. Radiol. 2011, 22, 755-761. [CrossRef]

40. Brace, C.L. Radiofrequency and Microwave Ablation of the Liver, Lung, Kidney, and Bone: What Are the Differences? Curr. Probl. Diagn. Radiol. 2009, 38, 135-143. [CrossRef]

41. Ihara, H.; Gobara, H.; Hiraki, T.; Mitsuhashi, T.; Iguchi, T.; Fujiwara, H.; Matsui, Y.; Soh, J.; Toyooka, S.; Kanazawa, S. Radiofrequency Ablation of Lung Tumors Using a Multitined Expandable Electrode: Impact of the Electrode Array Diameter on Local Tumor Progression. J. Vasc. Interv. Radiol. 2016, 27, 87-95. [CrossRef]

42. Okuno, M.; Kawaguchi, Y.; De Bellis, M.; Vega, E.A.; Huang, S.Y.; Ahrar, K.; Gupta, S.; Vauthey, J.-N.; Odisio, B.C. A New Sequential Treatment Strategy for Multiple Colorectal Liver Metastases: Planned Incomplete Resection and Postoperative Completion Ablation for Intentionally-Untreated Tumors under Guidance of Cross-Sectional Imaging. Eur. J. Surg. Oncol. 2021, 47, 311-316. [CrossRef] [PubMed]

43. Foroutani, A. Laparoscopic Ultrasound versus Triphasic Computed Tomography for Detecting Liver Tumors. Arch. Surg. 2000, 135, 933. [CrossRef] [PubMed]

44. Berber, E.; Siperstein, A. Local Recurrence After Laparoscopic Radiofrequency Ablation of Liver Tumors: An Analysis of 1032 Tumors. Ann. Surg. Oncol. 2008, 15, 2757-2764. [CrossRef] [PubMed]

45. Kennedy, T.J.; Cassera, M.A.; Khajanchee, Y.S.; Diwan, T.S.; Hammill, C.W.; Hansen, P.D. Laparoscopic Radiofrequency Ablation for the Management of Colorectal Liver Metastases: 10-Year Experience: Laparoscopic RFA for CRLM. J. Surg. Oncol. 2013, 107, 324-328. [CrossRef] [PubMed]

46. Hammill, C.W.; Billingsley, K.G.; Cassera, M.A.; Wolf, R.F.; Ujiki, M.B.; Hansen, P.D. Outcome After Laparoscopic Radiofrequency Ablation of Technically Resectable Colorectal Liver Metastases. Ann. Surg. Oncol. 2011, 18, 1947-1954. [CrossRef] 
47. Vogl, T.J.; Farshid, P.; Naguib, N.N.N.; Darvishi, A.; Bazrafshan, B.; Mbalisike, E.; Burkhard, T.; Zangos, S. Thermal Ablation of Liver Metastases from Colorectal Cancer: Radiofrequency, Microwave and Laser Ablation Therapies. Radiol. Med. 2014, 119, 451-461. [CrossRef]

48. Stoltz, A.; Gagnière, J.; Dupré, A.; Rivoire, M. Radiofrequency Ablation for Colorectal Liver Metastases. J. Visc. Surg. 2014, 151, S33-S44. [CrossRef]

49. Wang, Y.; Zheng, J.; Chen, H.; Hu, C.; Sun, B.; Wang, H.; Shi, Q.; Long, J.; Zhang, H.; Li, W. A Prognostic Nomogram for Colorectal Cancer Liver Metastases after Percutaneous Thermal Ablation. Int. J. Hyperth. 2018, 34, 853-862. [CrossRef]

50. Wu, H.; Liu, G.; Zhang, Z.; Wu, W.; Meng, Y.; Wang, S.; Yang, W.; Yan, K. Nomogram Including Chemotherapy Response for Prediction of Intrahepatic Progression-Free Survival in Patients with Colorectal Liver Metastasis through Chemotherapy Followed by Radiofrequency Ablation. Int. J. Hyperth. 2021, 38, 633-639. [CrossRef]

51. Calandri, M.; Yamashita, S.; Gazzera, C.; Fonio, P.; Veltri, A.; Bustreo, S.; Sheth, R.A.; Yevich, S.M.; Vauthey, J.-N.; Odisio, B.C. Ablation of Colorectal Liver Metastasis: Interaction of Ablation Margins and RAS Mutation Profiling on Local Tumour Progression-Free Survival. Eur. Radiol. 2018, 28, 2727-2734. [CrossRef]

52. Han, K.; Kim, J.H.; Yang, S.G.; Park, S.H.; Choi, H.-K.; Chun, S.-Y.; Kim, P.N.; Park, J.; Lee, M. A Single-Center Retrospective Analysis of Periprocedural Variables Affecting Local Tumor Progression after Radiofrequency Ablation of Colorectal Cancer Liver Metastases. Radiology 2021, 298, 212-218. [CrossRef]

53. Fan, H.; Wang, X.; Qu, J.; Lu, W.; Pang, Z.; Shao, T.; Xia, J.; Wang, H.; Li, G.; Zhang, Y.; et al. Periprocedural Risk Factors for Incomplete Radiofrequency Ablation of Liver Metastases from Colorectal Cancer: A Single-Center Retrospective Analysis. Int. J. Hyperth. 2021, 38, 985-994. [CrossRef]

54. Wang, C.-Z.; Yan, G.-X.; Xin, H.; Liu, Z.-Y. Oncological Outcomes and Predictors of Radiofrequency Ablation of Colorectal Cancer Liver Metastases. World J. Gastrointest. Oncol. 2020, 12, 1044-1055. [CrossRef] [PubMed]

55. Shady, W.; Petre, E.N.; Do, K.G.; Gonen, M.; Yarmohammadi, H.; Brown, K.T.; Kemeny, N.E.; D'Angelica, M.; Kingham, P.T.; Solomon, S.B.; et al. Percutaneous Microwave versus Radiofrequency Ablation of Colorectal Liver Metastases: Ablation with Clear Margins (A0) Provides the Best Local Tumor Control. J. Vasc. Interv. Radiol. 2018, 29, 268-275. [CrossRef] [PubMed]

56. Shady, W.; Petre, E.N.; Vakiani, E.; Ziv, E.; Gonen, M.; Brown, K.T.; Kemeny, N.E.; Solomon, S.B.; Solit, D.B.; Sofocleous, C.T. Kras Mutation Is a Marker of Worse Oncologic Outcomes after Percutaneous Radiofrequency Ablation of Colorectal Liver Metastases. Oncotarget 2017, 8, 66117-66127. [CrossRef] [PubMed]

57. Keil, S.; Bruners, P.; Schiffl, K.; Sedlmair, M.; Mühlenbruch, G.; Günther, R.W.; Das, M.; Mahnken, A.H. Radiofrequency Ablation of Liver Metastases-Software-Assisted Evaluation of the Ablation Zone in MDCT: Tumor-Free Follow-Up Versus Local Recurrent Disease. Cardiovasc. Interv. Radiol. 2010, 33, 297-306. [CrossRef] [PubMed]

58. Laimer, G.; Jaschke, N.; Schullian, P.; Putzer, D.; Eberle, G.; Solbiati, M.; Solbiati, L.; Goldberg, S.N.; Bale, R. Volumetric Assessment of the Periablational Safety Margin after Thermal Ablation of Colorectal Liver Metastases. Eur. Radiol. 2021, 31, 6489-6499. [CrossRef]

59. Sandu, R.-M.; Paolucci, I.; Ruiter, S.J.S.; Sznitman, R.; de Jong, K.P.; Freedman, J.; Weber, S.; Tinguely, P. Volumetric Quantitative Ablation Margins for Assessment of Ablation Completeness in Thermal Ablation of Liver Tumors. Front. Oncol. 2021, 11, 623098. [CrossRef]

60. Yang, G.; Wang, G.; Sun, J.; Xiong, Y.; Li, W.; Tang, T.; Li, J. The Prognosis of Radiofrequency Ablation versus Hepatic Resection for Patients with Colorectal Liver Metastases: A Systematic Review and Meta-Analysis Based on 22 Studies. Int. J. Surg. 2021, 87, 105896. [CrossRef]

61. Kurilova, I.; Bendet, A.; Petre, E.N.; Boas, F.E.; Kaye, E.; Gonen, M.; Covey, A.; Brody, L.A.; Brown, K.T.; Kemeny, N.E.; et al. Factors Associated With Local Tumor Control and Complications After Thermal Ablation of Colorectal Cancer Liver Metastases: A 15-Year Retrospective Cohort Study. Clin. Colorectal Cancer 2021, 20, e82-e95. [CrossRef]

62. Odisio, B.C.; Yamashita, S.; Huang, S.Y.; Harmoush, S.; Kopetz, S.E.; Ahrar, K.; Shin Chun, Y.; Conrad, C.; Aloia, T.A.; Gupta, S.; et al. Local Tumour Progression after Percutaneous Ablation of Colorectal Liver Metastases According to RAS Mutation Status. Br. J. Surg. 2017, 104, 760-768. [CrossRef]

63. Yamashita, S.; Odisio, B.C.; Huang, S.Y.; Kopetz, S.E.; Ahrar, K.; Chun, Y.S.; Conrad, C.; Aloia, T.A.; Gupta, S.; Harmoush, S.; et al. Embryonic Origin of Primary Colon Cancer Predicts Survival in Patients Undergoing Ablation for Colorectal Liver Metastases. Eur. J. Surg. Oncol. 2017, 43, 1040-1049. [CrossRef]

64. Odisio, B.C.; Yamashita, S.; Huang, S.Y.; Kopetz, S.E.; Ahrar, K.; Mizuno, T.; Conrad, C.; Aloia, T.A.; Chun, Y.S.; Gupta, S.; et al. Impact of Prior Hepatectomy History on Local Tumor Progression after Percutaneous Ablation of Colorectal Liver Metastases. J. Vasc. Interv. Radiol. 2018, 29, 395-403. [CrossRef]

65. Sofocleous, C.T.; Garg, S.; Petrovic, L.M.; Gonen, M.; Petre, E.N.; Klimstra, D.S.; Solomon, S.B.; Brown, K.T.; Brody, L.A.; Covey, A.M.; et al. Ki-67 Is a Prognostic Biomarker of Survival after Radiofrequency Ablation of Liver Malignancies. Ann. Surg. Oncol. 2012, 19, 4262-4269. [CrossRef]

66. Sotirchos, V.S.; Petrovic, L.M.; Gönen, M.; Klimstra, D.S.; Do, R.K.G.; Petre, E.N.; Garcia, A.R.; Barlas, A.; Erinjeri, J.P.; Brown, K.T.; et al. Colorectal Cancer Liver Metastases: Biopsy of the Ablation Zone and Margins Can Be Used to Predict Oncologic Outcome. Radiology 2016, 280, 949-959. [CrossRef] 
67. Ruers, T.; Van Coevorden, F.; Punt, C.J.A.; Pierie, J.-P.E.N.; Borel-Rinkes, I.; Ledermann, J.A.; Poston, G.; Bechstein, W.; Lentz, M.-A.; Mauer, M.; et al. Local Treatment of Unresectable Colorectal Liver Metastases: Results of a Randomized Phase II Trial. J. Natl. Cancer Inst. 2017, 109. [CrossRef] [PubMed]

68. Kazemier, G. Unresectable Colorectal Cancer Liver Metastases Treated by Intraoperative Radiofrequency Ablation with or without Resection. Br. J. Surg. 2012, 99, 558-565. [CrossRef] [PubMed]

69. Meijerink, M.R.; Puijk, R.S.; van Tilborg, A.A.J.M.; Henningsen, K.H.; Fernandez, L.G.; Neyt, M.; Heymans, J.; Frankema, J.S.; de Jong, K.P.; Richel, D.J.; et al. Radiofrequency and Microwave Ablation Compared to Systemic Chemotherapy and to Partial Hepatectomy in the Treatment of Colorectal Liver Metastases: A Systematic Review and Meta-Analysis. Cardiovasc. Interv. Radiol. 2018, 41, 1189-1204. [CrossRef] [PubMed]

70. Gavriilidis, P.; Roberts, K.J.; de'Angelis, N.; Aldrighetti, L.; Sutcliffe, R.P. Recurrence and Survival Following Microwave, Radiofrequency Ablation, and Hepatic Resection of Colorectal Liver Metastases: A Systematic Review and Network MetaAnalysis. Hepatobiliary Pancreat. Dis. Int. 2021, 20, 307-314. [CrossRef]

71. Leblanc, F.; Fonck, M.; Brunet, R.; Becouarn, Y.; Mathoulin-Pélissier, S.; Evrard, S. Comparison of Hepatic Recurrences after Resection or Intraoperative Radiofrequency Ablation Indicated by Size and Topographical Characteristics of the Metastases. Eur. J. Surg. Oncol. 2008, 34, 185-190. [CrossRef]

72. Tanis, E.; Nordlinger, B.; Mauer, M.; Sorbye, H.; van Coevorden, F.; Gruenberger, T.; Schlag, P.M.; Punt, C.J.A.; Ledermann, J.; Ruers, T.J.M. Local Recurrence Rates after Radiofrequency Ablation or Resection of Colorectal Liver Metastases. Analysis of the European Organisation for Research and Treatment of Cancer \#40004 and \#40983. Eur. J. Cancer 2014, 50, 912-919. [CrossRef]

73. Dupré, A.; Jones, R.P.; Diaz-Nieto, R.; Fenwick, S.W.; Poston, G.J.; Malik, H.Z. Curative-Intent Treatment of Recurrent Colorectal Liver Metastases: A Comparison between Ablation and Resection. Eur. J. Surg. Oncol. 2017, 43, 1901-1907. [CrossRef] [PubMed]

74. Otto, G.; Düber, C.; Hoppe-Lotichius, M.; König, J.; Heise, M.; Bernhard Pitton, M. Radiofrequency Ablation as First-Line Treatment in Patients With Early Colorectal Liver Metastases Amenable to Surgery. Ann. Surg. 2010, 251, 796-803. [CrossRef]

75. Dijkstra, M.; Nieuwenhuizen, S.; Puijk, R.S.; Timmer, F.E.F.; Geboers, B.; Schouten, E.A.C.; Opperman, J.; Scheffer, H.J.; de Vries, J.J.J.; Swijnenburg, R.-J.; et al. Thermal Ablation Compared to Partial Hepatectomy for Recurrent Colorectal Liver Metastases: An Amsterdam Colorectal Liver Met Registry (AmCORE) Based Study. Cancers 2021, 13, 2769. [CrossRef]

76. Carrafiello, G.; Laganà, D.; Mangini, M.; Fontana, F.; Dionigi, G.; Boni, L.; Rovera, F.; Cuffari, S.; Fugazzola, C. Microwave Tumors Ablation: Principles, Clinical Applications and Review of Preliminary Experiences. Int. J. Surg. 2008, 6, S65-S69. [CrossRef] [PubMed]

77. Shi, Y.; Wang, Z.; Chi, J.; Shi, D.; Wang, T.; Cui, D.; Lin, Y.; Zhai, B. Long-Term Results of Percutaneous Microwave Ablation for Colorectal Liver Metastases. HPB 2021, 23, 37-45. [CrossRef]

78. Qin, S.; Liu, G.-J.; Huang, M.; Huang, J.; Luo, Y.; Wen, Y.; Wang, Y.; Chen, L. The Local Efficacy and Influencing Factors of Ultrasound-Guided Percutaneous Microwave Ablation in Colorectal Liver Metastases: A Review of a 4-Year Experience at a Single Center. Int. J. Hyperth. 2019, 36, 36-43. [CrossRef]

79. Engstrand, J.; Nilsson, H.; Jansson, A.; Isaksson, B.; Freedman, J.; Lundell, L.; Jonas, E. A Multiple Microwave Ablation Strategy in Patients with Initially Unresectable Colorectal Cancer Liver Metastases-A Safety and Feasibility Study of a New Concept. Eur. J. Surg. Oncol. 2014, 40, 1488-1493. [CrossRef] [PubMed]

80. Shibata, T.; Niinobu, T.; Ogata, N.; Takami, M. Microwave Coagulation Therapy for Multiple Hepatic Metastases from Colorectal Carcinoma. Cancer 2000, 89, 276-284. [CrossRef]

81. Song, P.; Sheng, L.; Sun, Y.; An, Y.; Guo, Y.; Zhang, Y. The Clinical Utility and Outcomes of Microwave Ablation for Colorectal Cancer Liver Metastases. Oncotarget 2017, 8, 51792-51799. [CrossRef]

82. Tanaka, K.; Shimada, H.; Nagano, Y.; Endo, I.; Sekido, H.; Togo, S. Outcome after Hepatic Resection versus Combined Resection and Microwave Ablation for Multiple Bilobar Colorectal Metastases to the Liver. Surgery 2006, 139, 263-273. [CrossRef]

83. Di Martino, M.; Rompianesi, G.; Mora-Guzmán, I.; Martín-Pérez, E.; Montalti, R.; Troisi, R.I. Systematic Review and Meta-Analysis of Local Ablative Therapies for Resectable Colorectal Liver Metastases. Eur. J. Surg. Oncol. 2020, 46, 772-781. [CrossRef]

84. Yang, B.; Li, Y. A Comparative Study of Laparoscopic Microwave Ablation with Laparoscopic Radiofrequency Ablation for Colorectal Liver Metastasis. J. Buon 2017, 22, 667-672.

85. Huo, Y.R.; Eslick, G.D. Microwave Ablation Compared to Radiofrequency Ablation for Hepatic Lesions: A Meta-Analysis. J. Vasc. Interv. Radiol. 2015, 26, 1139-1146. [CrossRef]

86. Correa-Gallego, C.; Fong, Y.; Gonen, M.; D’Angelica, M.I.; Allen, P.J.; DeMatteo, R.P.; Jarnagin, W.R.; Kingham, T.P. A Retrospective Comparison of Microwave Ablation vs. Radiofrequency Ablation for Colorectal Cancer Hepatic Metastases. Ann. Surg. Oncol. 2014, 21, 4278-4283. [CrossRef] [PubMed]

87. Froelich, M.F.; Schnitzer, M.L.; Rathmann, N.; Tollens, F.; Unterrainer, M.; Rennebaum, S.; Seidensticker, M.; Ricke, J.; Rübenthaler, J.; Kunz, W.G. Cost-Effectiveness Analysis of Local Ablation and Surgery for Liver Metastases of Oligometastatic Colorectal Cancer. Cancers 2021, 13, 1507. [CrossRef]

88. Abdalla, E.K.; Vauthey, J.-N.; Ellis, L.M.; Ellis, V.; Pollock, R.; Broglio, K.R.; Hess, K.; Curley, S.A. Recurrence and Outcomes Following Hepatic Resection, Radiofrequency Ablation, and Combined Resection/Ablation for Colorectal Liver Metastases. Ann. Surg. 2004, 239, 818-827. [CrossRef] [PubMed]

89. Kim, K.H.; Yoon, Y.S.; Yu, C.S.; Kim, T.W.; Kim, H.J.; Kim, P.N.; Ha, H.K.; Kim, J.C. Comparative Analysis of Radiofrequency Ablation and Surgical Resection for Colorectal Liver Metastases. J. Korean Surg. Soc. 2011, 81, 25. [CrossRef] 
90. Schiffman, S.C.; Bower, M.; Brown, R.E.; Martin, R.C.G.; McMasters, K.M.; Scoggins, C.R. Hepatectomy Is Superior to Thermal Ablation for Patients with a Solitary Colorectal Liver Metastasis. J. Gastrointest. Surg. 2010, 14, 1881-1887. [CrossRef]

91. Tinguely, P.; Dal, G.; Bottai, M.; Nilsson, H.; Freedman, J.; Engstrand, J. Microwave Ablation versus Resection for Colorectal Cancer Liver Metastases-A Propensity Score Analysis from a Population-Based Nationwide Registry. Eur. J. Surg. Oncol. 2020, 46, 476-485. [CrossRef] [PubMed]

92. Bageacu, S.; Kaczmarek, D.; Lacroix, M.; Dubois, J.; Forest, J.; Porcheron, J. Cryosurgery for Resectable and Unresectable Hepatic Metastases from Colorectal Cancer. Eur. J. Surg. Oncol. 2007, 33, 590-596. [CrossRef]

93. Bhardwaj, N.; Strickland, A.D.; Ahmad, F.; Atanesyan, L.; West, K.; Lloyd, D.M. A Comparative Histological Evaluation of the Ablations Produced by Microwave, Cryotherapy and Radiofrequency in the Liver. Pathology 2009, 41, 168-172. [CrossRef]

94. Seifert, J.K.; Morris, D.L. World Survey on the Complications of Hepatic and Prostate Cryotherapy. World J. Surg. 1999, 23, 109-114. [CrossRef]

95. Ng, K.M.; Chua, T.C.; Saxena, A.; Zhao, J.; Chu, F.; Morris, D.L. Two Decades of Experience with Hepatic Cryotherapy for Advanced Colorectal Metastases. Ann. Surg. Oncol. 2012, 19, 1276-1283. [CrossRef]

96. Littrup, P.J.; Aoun, H.D.; Adam, B.; Krycia, M.; Prus, M.; Shields, A. Percutaneous Cryoablation of Hepatic Tumors: Long-Term Experience of a Large U.S. Series. Abdom. Radiol. 2016, 41, 767-780. [CrossRef] [PubMed]

97. Pathak, S.; Jones, R.; Tang, J.M.F.; Parmar, C.; Fenwick, S.; Malik, H.; Poston, G. Ablative Therapies for Colorectal Liver Metastases: A Systematic Review: Ablation for Colorectal Liver Metastases. Colorectal Dis. 2011, 13, e252-e265. [CrossRef] [PubMed]

98. Korpan, N.N. Hepatic Cryosurgery for Liver Metastases: Long-Term Follow-Up. Ann. Surg. 1997, 225, 193-201. [CrossRef]

99. Bala, M.M.; Riemsma, R.P.; Wolff, R.; Pedziwiatr, M.; Mitus, J.W.; Storman, D.; Swierz, M.J.; Kleijnen, J. Cryotherapy for Liver Metastases. Cochrane Database Syst. Rev. 2019. [CrossRef]

100. Niu, L.; Zhou, L.; Xu, K.; Mu, F. Cryosurgery for Colorectal Liver Metastases. Ann. Palliat. Med. 2013, 2, 130-140. [CrossRef]

101. Camacho, J.C.; Petre, E.N.; Sofocleous, C.T. Thermal Ablation of Metastatic Colon Cancer to the Liver. Semin. Interv. Radiol. 2019, 36, 310-318. [CrossRef] [PubMed]

102. Jiang, T.; Tian, G.; Bao, H.; Chen, F.; Deng, Z.; Li, J.; Chai, W. EUS Dating with Laser Ablation against the Caudate Lobe or Left Liver Tumors: A Win-Win Proposition? Cancer Biol. Ther. 2018, 19, 145-152. [CrossRef]

103. Skinner, M.G.; Iizuka, M.N.; Kolios, M.C.; Sherar, M.D. A Theoretical Comparison of Energy Sources-Microwave, Ultrasound and Laser-For Interstitial Thermal Therapy. Phys. Med. Biol. 1998, 43, 3535-3547. [CrossRef]

104. Muralidharan, V.; Malcontenti-Wilson, C.; Christophi, C. Interstitial Laser Hyperthermia for Colorectal Liver Metastases: The Effect of Thermal Sensitization and the Use of a Cylindrical Diffuser Tip on Tumor Necrosis. J. Clin. Laser Med. Surg. 2002, 20, 189-196. [CrossRef] [PubMed]

105. Vogl, T.J.; Straub, R.; Zangos, S.; Mack, M.G.; Eichler, K. MR-Guided Laser-Induced Thermotherapy (LITT) of Liver Tumours: Experimental and Clinical Data. Int. J. Hyperth. 2004, 20, 713-724. [CrossRef] [PubMed]

106. Stollberger, R.; Ascher, P.W.; Huber, D.; Renhart, W.; Radner, H.; Ebner, F. Invited. Temperature Monitoring of Interstitial Thermal Tissue Coagulation Using MR Phase Images. J. Magn. Reson. Imaging 1998, 8, 188-196. [CrossRef]

107. Vogl, T.J.; Straub, R.; Eichler, K.; Woitaschek, D.; Mack, M.G. Malignant Liver Tumors Treated with MR Imaging-Guided Laser-Induced Thermotherapy: Experience with Complications in 899 Patients (2,520 Lesions). Radiology 2002, 225, 367-377. [CrossRef] [PubMed]

108. Vogl, T.J.; Dommermuth, A.; Heinle, B.; Nour-Eldin, N.-E.A.; Lehnert, T.; Eichler, K.; Zangos, S.; Bechstein, W.O.; Naguib, N.N.N. Colorectal Cancer Liver Metastases: Long-Term Survival and Progression-Free Survival After Thermal Ablation Using Magnetic Resonance-Guided Laser-Induced Interstitial Thermotherapy in 594 Patients. Investig. Radiol. 2014, 49, 48-56. [CrossRef]

109. Puls, R.; Langner, S.; Rosenberg, C.; Hegenscheid, K.; Kuehn, J.P.; Noeckler, K.; Hosten, N. Laser Ablation of Liver Metastases from Colorectal Cancer with MR Thermometry: 5-Year Survival. J. Vasc. Interv. Radiol. 2009, 20, 225-234. [CrossRef]

110. ter Haar, G.; Coussios, C. High Intensity Focused Ultrasound: Physical Principles and Devices. Int. J. Hyperth. 2007, 23, 89-104. [CrossRef]

111. Park, M.Y.; Jung, S.E.; Cho, S.H.; Piao, X.-H.; Hahn, S.T.; Han, J.-Y.; Woo, I.S. Preliminary Experience Using High Intensity Focused Ultrasound for Treating Liver Metastasis from Colon and Stomach Cancer. Int. J. Hyperth. 2009, 25, 180-188. [CrossRef]

112. Diana, M.; Schiraldi, L.; Liu, Y.-Y.; Memeo, R.; Mutter, D.; Pessaux, P.; Marescaux, J. High Intensity Focused Ultrasound (HIFU) Applied to Hepato-Bilio-Pancreatic and the Digestive System-Current State of the Art and Future Perspectives. Hepatobiliary Surg. Nutr. 2016, 5, 329-344. [CrossRef]

113. Dupré, A.; Melodelima, D.; Pérol, D.; Chen, Y.; Vincenot, J.; Chapelon, J.-Y.; Rivoire, M. First Clinical Experience of Intra-Operative High Intensity Focused Ultrasound in Patients with Colorectal Liver Metastases: A Phase I-IIa Study. PLoS ONE 2015, 10, e0118212. [CrossRef] [PubMed]

114. Mavrogenis, A.F.; Angelini, A.; Vottis, C.; Pala, E.; Calabrò, T.; Papagelopoulos, P.J.; Ruggieri, P. Modern Palliative Treatments for Metastatic Bone Disease: Awareness of Advantages, Disadvantages, and Guidance. Clin. J. Pain 2016, 32, 337-350. [CrossRef] [PubMed]

115. Hurwitz, M.D.; Ghanouni, P.; Kanaev, S.V.; Iozeffi, D.; Gianfelice, D.; Fennessy, F.M.; Kuten, A.; Meyer, J.E.; LeBlang, S.D.; Roberts, A.; et al. Magnetic Resonance-Guided Focused Ultrasound for Patients With Painful Bone Metastases: Phase III Trial Results. J. Natl. Cancer Inst. 2014, 106. [CrossRef] [PubMed] 
116. Li, C.; Zhang, W.; Zhang, R.; Zhang, L.; Wu, P.; Zhang, F. Therapeutic Effects and Prognostic Factors in High-Intensity Focused Ultrasound Combined with Chemoembolisation for Larger Hepatocellular Carcinoma. Eur. J. Cancer 2010, 46, $2513-2521$. [CrossRef]

117. Ji, Y.; Zhu, J.; Zhu, L.; Zhu, Y.; Zhao, H. High-Intensity Focused Ultrasound Ablation for Unresectable Primary and Metastatic Liver Cancer: Real-World Research in a Chinese Tertiary Center With 275 Cases. Front. Oncol. 2020, 10, 519164. [CrossRef]

118. Yang, T.; Ng, D.M.; Du, N.; He, N.; Dai, X.; Chen, P.; Wu, F.; Chen, B.; Fan, X.; Yan, K.; et al. HIFU for the Treatment of Difficult Colorectal Liver Metastases with Unsuitable Indications for Resection and Radiofrequency Ablation: A Phase I Clinical Trial. Surg. Endosc. 2021, 35, 2306-2315. [CrossRef] [PubMed]

119. Lee, E.W.; Loh, C.T.; Kee, S.T. Imaging Guided Percutaneous Irreversible Electroporation: Ultrasound and Immunohistological Correlation. Technol. Cancer Res. Treat. 2007, 6, 287-293. [CrossRef] [PubMed]

120. Lee, E.W.; Thai, S.; Kee, S.T. Irreversible Electroporation: A Novel Image-Guided Cancer Therapy. Gut Liver 2010, 4, S99. [CrossRef]

121. Davalos, R.V.; Mir, L.M.; Rubinsky, B. Tissue Ablation with Irreversible Electroporation. Ann. Biomed. Eng. 2005, 33, $223-231$. [CrossRef]

122. Faroja, M.; Ahmed, M.; Appelbaum, L.; Ben-David, E.; Moussa, M.; Sosna, J.; Nissenbaum, I.; Goldberg, S.N. Irreversible Electroporation Ablation: Is All the Damage Nonthermal? Radiology 2013, 266, 462-470. [CrossRef]

123. Cornelis, F.H.; Cindrič, H.; Kos, B.; Fujimori, M.; Petre, E.N.; Miklavčič, D.; Solomon, S.B.; Srimathveeravalli, G. Peri-Tumoral Metallic Implants Reduce the Efficacy of Irreversible Electroporation for the Ablation of Colorectal Liver Metastases. Cardiovasc. Interv. Radiol. 2020, 43, 84-93. [CrossRef]

124. Scheffer, H.J.; Nielsen, K.; de Jong, M.C.; van Tilborg, A.A.J.M.; Vieveen, J.M.; Bouwman, A.R.A.; Meijer, S.; van Kuijk, C.; van den Tol, P.M.P.; Maijerink, M.R. Irreversible Electroporation for Nonthermal Tumor Ablation in the Clinical Setting: A Systematic Review of Safety and Efficacy. J. Vasc. Interv. Radiol. 2014, 25, 997-1011. [CrossRef] [PubMed]

125. Scheffer, H.J.; Melenhorst, M.C.A.M.; Echenique, A.M.; Nielsen, K.; van Tilborg, A.A.J.M.; van den Bos, W.; Vroomen, L.G.P.H.; van den Tol, P.M.P.; Meijerink, M.R. Irreversible Electroporation for Colorectal Liver Metastases. Tech. Vasc. Interv. Radiol. 2015, 18, 159-169. [CrossRef]

126. Tameez Ud Din, A.; Tameez-ud-din, A.; Chaudhary, F.M.D.; Chaudhary, N.A.; Siddiqui, K.H. Irreversible Electroporation For Liver Tumors: A Review Of Literature. Cureus 2019, 11. [CrossRef] [PubMed]

127. Fredericks, C.; Arslan, B.; Mullane, M.; Firfer, B.L.; Chan, E.Y. Needle Tract Seeding Following Irreversible Electroporation (IRE) of Metastatic Colorectal Carcinoma to the Liver. Cardiovasc. Interv. Radiol. 2015, 38, 1349-1351. [CrossRef] [PubMed]

128. Dollinger, M.; Beyer, L.P.; Haimerl, M.; Niessen, C.; Jung, E.-M.; Zeman, F.; Stroszczynski, C.; Wiggermann, P. Adverse Effects of Irreversible Electroporation of Malignant Liver Tumors under CT Fluoroscopic Guidance: A Single-Center Experience. Diagn. Interv. Radiol. 2015, 21, 471-475. [CrossRef]

129. Verloh, N.; Jensch, I.; Lürken, L.; Haimerl, M.; Dollinger, M.; Renner, P.; Wiggermann, P.; Werner, J.M.; Zeman, F.; Stroszczynski, C.; et al. Similar Complication Rates for Irreversible Electroporation and Thermal Ablation in Patients with Hepatocellular Tumors. Radiol. Oncol. 2019, 53, 116-122. [CrossRef]

130. Meijerink, M.R.; Ruarus, A.H.; Vroomen, L.G.P.H.; Puijk, R.S.; Geboers, B.; Nieuwenhuizen, S.; van den Bemd, B.A.T.; Nielsen, K.; de Vries, J.J.J.; van Lienden, K.P.; et al. Irreversible Electroporation to Treat Unresectable Colorectal Liver Metastases (COLDFIRE-2): A Phase II, Two-Center, Single-Arm Clinical Trial. Radiology 2021, 299, 470-480. [CrossRef]

131. Schicho, A.; Niessen, C.; Haimerl, M.; Wiesinger, I.; Stroszczynski, C.; Beyer, L.P.; Wiggermann, P. Long-Term Survival after Percutaneous Irreversible Electroporation of Inoperable Colorectal Liver Metastases. Cancer Manag. Res. 2018, 11, 317-322. [CrossRef]

132. Potters, L.; Kavanagh, B.; Galvin, J.M.; Hevezi, J.M.; Janjan, N.A.; Larson, D.A.; Mehta, M.P.; Ryu, S.; Steinberg, M.; Timmerman, R.; et al. American Society for Therapeutic Radiology and Oncology (ASTRO) and American College of Radiology (ACR) Practice Guideline for the Performance of Stereotactic Body Radiation Therapy. Int. J. Radiat. Oncol. Biol. Phys. 2010, 76, $326-332$. [CrossRef]

133. Romesser, P.B.; Tyagi, N.; Crane, C.H. Magnetic Resonance Imaging-Guided Adaptive Radiotherapy for Colorectal Liver Metastases. Cancers 2021, 13, 1636. [CrossRef]

134. Molla, M.; Fernandez-Plana, J.; Albiol, S.; Fondevila, C.; Vollmer, I.; Cases, C.; Garcia-Criado, A.; Capdevila, J.; Conill, C.; Fundora, Y.; et al. Limited Liver or Lung Colorectal Cancer Metastases. Systemic Treatment, Surgery, Ablation or SBRT. J. Clin. Med. 2021, 10, 2131. [CrossRef] [PubMed]

135. Ahmed, K.A.; Caudell, J.J.; El-Haddad, G.; Berglund, A.E.; Welsh, E.A.; Yue, B.; Hoffe, S.E.; Naghavi, A.O.; Abuodeh, Y.A.; Frakes, J.M.; et al. Radiosensitivity Differences Between Liver Metastases Based on Primary Histology Suggest Implications for Clinical Outcomes After Stereotactic Body Radiation Therapy. Int. J. Radiat. Oncol. Biol. Phys. 2016, 95, 1399-1404. [CrossRef] [PubMed]

136. McPartlin, A.; Swaminath, A.; Wang, R.; Pintilie, M.; Brierley, J.; Kim, J.; Ringash, J.; Wong, R.; Dinniwell, R.; Craig, T.; et al. Long-Term Outcomes of Phase 1 and 2 Studies of SBRT for Hepatic Colorectal Metastases. Int. J. Radiat. Oncol. Biol. Phys. 2017, 99, 388-395. [CrossRef] [PubMed]

137. Comito, T.; Cozzi, L.; Clerici, E.; Campisi, M.C.; Liardo, R.L.E.; Navarria, P.; Ascolese, A.; Tozzi, A.; Iftode, C.; De Rose, F.; et al. Stereotactic Ablative Radiotherapy (SABR) in Inoperable Oligometastatic Disease from Colorectal Cancer: A Safe and Effective Approach. BMC Cancer 2014, 14, 619. [CrossRef] 
138. Aitken, K.; Tree, A.; Thomas, K.; Nutting, C.; Hawkins, M.; Tait, D.; Mandeville, H.; Ahmed, M.; Lalondrelle, S.; Miah, A.; et al. Initial UK Experience of Stereotactic Body Radiotherapy for Extracranial Oligometastases: Can We Change the Therapeutic Paradigm? Clin. Oncol. 2015, 27, 411-419. [CrossRef]

139. Palma, D.A.; Olson, R.; Harrow, S.; Gaede, S.; Louie, A.V.; Haasbeek, C.; Mulroy, L.; Lock, M.; Rodrigues, G.B.; Yaremko, B.P.; et al. Stereotactic Ablative Radiotherapy versus Standard of Care Palliative Treatment in Patients with Oligometastatic Cancers (SABR-COMET): A Randomised, Phase 2, Open-Label Trial. Lancet 2019, 393, 2051-2058. [CrossRef]

140. Kamarinos, N.V.; Dawson, L.A.; Saltz, L.B.; Crane, C.H.; Overman, M.J.; Vauthey, J.-N.; Odisio, B.C.; Denys, A.; de Baère, T.; Pereira, P.L.; et al. Trials of Locoregional Therapies Inspired by SABR-COMET. Lancet 2020, 396, 956-957. [CrossRef]

141. Scorsetti, M.; Comito, T.; Tozzi, A.; Navarria, P.; Fogliata, A.; Clerici, E.; Mancosu, P.; Reggiori, G.; Rimassa, L.; Torzilli, G.; et al Final Results of a Phase II Trial for Stereotactic Body Radiation Therapy for Patients with Inoperable Liver Metastases from Colorectal Cancer. J. Cancer Res. Clin. Oncol. 2015, 141, 543-553. [CrossRef]

142. Klement, R.J.; Abbasi-Senger, N.; Adebahr, S.; Alheid, H.; Allgaeuer, M.; Becker, G.; Blanck, O.; Boda-Heggemann, J.; Brunner, T.; Duma, M.; et al. The Impact of Local Control on Overall Survival after Stereotactic Body Radiotherapy for Liver and Lung Metastases from Colorectal Cancer: A Combined Analysis of 388 Patients with 500 Metastases. BMC Cancer 2019, $19,173$. [CrossRef]

143. Franzese, C.; Comito, T.; Clerici, E.; Di Brina, L.; Tomatis, S.; Navarria, P.; Reggiori, G.; Viganò, L.; Poretti, D.; Pedicini, V.; et al. Liver Metastases from Colorectal Cancer: Propensity Score-Based Comparison of Stereotactic Body Radiation Therapy vs. Microwave Ablation. J. Cancer Res. Clin. Oncol. 2018, 144, 1777-1783. [CrossRef]

144. Nieuwenhuizen, S.; Dijkstra, M.; Puijk, R.S.; Timmer, F.E.F.; Nota, I.M.; Opperman, J.; van den Bemd, B.; Geboers, B.; Ruarus, A.H.; Schouten, E.A.C.; et al. Thermal Ablation versus Stereotactic Ablative Body Radiotherapy to Treat Unresectable Colorectal Liver Metastases: A Comparative Analysis from the Prospective Amsterdam CORE Registry. Cancers 2021, 13, 4303. [CrossRef]

145. Andratschke, N.; Alheid, H.; Allgäuer, M.; Becker, G.; Blanck, O.; Boda-Heggemann, J.; Brunner, T.; Duma, M.; Gerum, S.; Guckenberger, M.; et al. The SBRT Database Initiative of the German Society for Radiation Oncology (DEGRO): Patterns of Care and Outcome Analysis of Stereotactic Body Radiotherapy (SBRT) for Liver Oligometastases in 474 Patients with 623 Metastases. BMC Cancer 2018, 18, 283. [CrossRef] [PubMed]

146. Mahadevan, A.; Blanck, O.; Lanciano, R.; Peddada, A.; Sundararaman, S.; D'Ambrosio, D.; Sharma, S.; Perry, D.; Kolker, J.; Davis, J. Stereotactic Body Radiotherapy (SBRT) for Liver Metastasis-Clinical Outcomes from the International Multi-Institutional RSSearch ${ }^{\circledR}$ Patient Registry. Radiat. Oncol. 2018, 13, 26. [CrossRef] [PubMed]

147. Lien, W.M.; Ackerman, N.B. The Blood Supply of Experimental Liver Metastases. II. A Microcirculatory Study of the Normal and Tumor Vessels of the Liver with the Use of Perfused Silicone Rubber. Surgery 1970, 68, 334-340. [PubMed]

148. Mocellin, S.; Pilati, P.; Lise, M.; Nitti, D. Meta-Analysis of Hepatic Arterial Infusion for Unresectable Liver Metastases From Colorectal Cancer: The End of an Era? J. Clin. Oncol. 2007, 25, 5649-5654. [CrossRef]

149. Thiels, C.A.; D'Angelica, M.I. Hepatic Artery Infusion Pumps. J. Surg. Oncol. 2020, 122, 70-77. [CrossRef]

150. Guthoff, I.; Lotspeich, E.; Fester, C.; Wallin, I.; Schatz, M.; Ehrsson, H.; Kornmann, M. Hepatic Artery Infusion Using Oxaliplatin in Combination with 5-Fluorouracil, Folinic Acid and Mitomycin C: Oxaliplatin Pharmacokinetics and Feasibility. Anticancer Res. 2003, 23, 5203-5208. [PubMed]

151. van Riel, J.M.G.H.; van Groeningen, C.J.; Kedde, M.A.; Gall, H.; Leisink, J.M.A.; Gruia, G.; Pinedo, H.M.; van der Vijgh, W.J.F.; Giaccone, G. Continuous Administration of Irinotecan by Hepatic Arterial Infusion: A Phase I and Pharmacokinetic Study. Clin. Cancer Res. 2002, 8, 405-412. [PubMed]

152. Curley, S.A.; Chase, J.L.; Roh, M.S.; Hohn, D.C. Technical Considerations and Complications Associated with the Placement of 180 Implantable Hepatic Arterial Infusion Devices. Surgery 1993, 114, 928-935.

153. Barber, F.D.; Mavligit, G.; Kurzrock, R. Hepatic Arterial Infusion Chemotherapy for Metastatic Colorectal Cancer: A Concise Overview. Cancer Treat. Rev. 2004, 30, 425-436. [CrossRef] [PubMed]

154. Kemeny, N. Intrahepatic or Systemic Infusion of Fluorodeoxyuridine in Patients with Liver Metastases from Colorectal Carcinoma: A Randomized Trial. Ann. Intern. Med. 1987, 107, 459. [CrossRef] [PubMed]

155. Martin, J.K. Intra-Arterial Floxuridine versus Systemic Fluorouracil for Hepatic Metastases From Colorectal Cancer: A Randomized Trial. Arch. Surg. 1990, 125, 1022. [CrossRef] [PubMed]

156. Kerr, D.J.; McArdle, C.S.; Ledermann, J.; Taylor, I.; Sherlock, D.J.; Schlag, P.M.; Buckels, J.; Mayer, D.; Cain, D.; Stephens, R.J. Intrahepatic Arterial versus Intravenous Fluorouracil and Folinic Acid for Colorectal Cancer Liver Metastases: A Multicentre Randomised Trial. Lancet 2003, 361, 368-373. [CrossRef]

157. Harmantas, A.; Rotstein, L.E.; Langer, B. Regional versus Systemic Chemotherapy in the Treatment of Colorectal Carcinoma Metastatic to the Liver. Is There a Survival Difference? Meta-Analysis of the Published Literature. Cancer 1996, 78, 1639-1645. [CrossRef]

158. Stagg, R.J.; Venook, A.P.; Chase, J.L.; Lewis, B.J.; Warren, R.S.; Roh, M.; Mulvihill, S.J.; Grobman, B.J.; Rayner, A.A.; Hohn, D.C. Alternating Hepatic Intra-Arterial Floxuridine and Fluorouracil: A Less Toxic Regimen for Treatment of Liver Metastases From Colorectal Cancer. J. Natl. Cancer Inst. 1991, 83, 423-428. [CrossRef]

159. Kemeny, N.E.; Niedzwiecki, D.; Hollis, D.R.; Lenz, H.-J.; Warren, R.S.; Naughton, M.J.; Weeks, J.C.; Sigurdson, E.R.; Herndon, J.E.; Zhang, C.; et al. Hepatic Arterial Infusion versus Systemic Therapy for Hepatic Metastases from Colorectal Cancer: A Randomized Trial of Efficacy, Quality of Life, and Molecular Markers (CALGB 9481). J. Clin. Oncol. 2006, 24, 1395-1403. [CrossRef] 
160. Pilati, P.; Mammano, E.; Mocellin, S.; Tessari, E.; Lise, M.; Nitti, D. Hepatic Arterial Infusion for Unresectable Colorectal Liver Metastases Combined or Not with Systemic Chemotherapy. Anticancer Res. 2009, 29, 4139-4144.

161. Kemeny, N.E.; Melendez, F.D.H.; Capanu, M.; Paty, P.B.; Fong, Y.; Schwartz, L.H.; Jarnagin, W.R.; Patel, D.; D’Angelica, M. Conversion to Resectability Using Hepatic Artery Infusion plus Systemic Chemotherapy for the Treatment of Unresectable Liver Metastases from Colorectal Carcinoma. J. Clin. Oncol. 2009, 27, 3465-3471. [CrossRef]

162. Goéré, D.; Deshaies, I.; de Baere, T.; Boige, V.; Malka, D.; Dumont, F.; Dromain, C.; Ducreux, M.; Elias, D. Prolonged Survival of Initially Unresectable Hepatic Colorectal Cancer Patients Treated With Hepatic Arterial Infusion of Oxaliplatin Followed by Radical Surgery of Metastases. Ann. Surg. 2010, 251, 686-691. [CrossRef]

163. Ducreux, M.; Ychou, M.; Laplanche, A.; Gamelin, E.; Lasser, P.; Husseini, F.; Quenet, F.; Viret, F.; Jacob, J.-H.; Boige, V.; et al. Hepatic Arterial Oxaliplatin Infusion Plus Intravenous Chemotherapy in Colorectal Cancer With Inoperable Hepatic Metastases: A Trial of the Gastrointestinal Group of the Fédération Nationale Des Centres de Lutte Contre Le Cancer. J. Clin. Oncol. 2005, 23, 4881-4887. [CrossRef] [PubMed]

164. D’Angelica, M.I.; Correa-Gallego, C.; Paty, P.B.; Cercek, A.; Gewirtz, A.N.; Chou, J.F.; Capanu, M.; Kingham, T.P.; Fong, Y.; DeMatteo, R.P.; et al. Phase II Trial of Hepatic Artery Infusional and Systemic Chemotherapy for Patients With Unresectable Hepatic Metastases From Colorectal Cancer: Conversion to Resection and Long-Term Outcomes. Ann. Surg. 2015, 261, 353-360. [CrossRef] [PubMed]

165. Lévi, F.A.; Boige, V.; Hebbar, M.; Smith, D.; Lepère, C.; Focan, C.; Karaboué, A.; Guimbaud, R.; Carvalho, C.; Tumolo, S.; et al. Conversion to Resection of Liver Metastases from Colorectal Cancer with Hepatic Artery Infusion of Combined Chemotherapy and Systemic Cetuximab in Multicenter Trial OPTILIV. Ann. Oncol. 2016, 27, 267-274. [CrossRef]

166. Lim, A.; Le Sourd, S.; Senellart, H.; Luet, D.; Douane, F.; Perret, C.; Bouvier, A.; Métairie, S.; Cauchin, E.; Rougier, P.; et al. Hepatic Arterial Infusion Chemotherapy for Unresectable Liver Metastases of Colorectal Cancer: A Multicenter Retrospective Study. Clin. Colorectal Cancer 2017, 16, 308-315. [CrossRef] [PubMed]

167. Pak, L.M.; Kemeny, N.E.; Capanu, M.; Chou, J.F.; Boucher, T.; Cercek, A.; Balachandran, V.P.; Kingham, T.P.; Allen, P.J.; DeMatteo, R.P.; et al. Prospective Phase II Trial of Combination Hepatic Artery Infusion and Systemic Chemotherapy for Unresectable Colorectal Liver Metastases: Long Term Results and Curative Potential. J. Surg. Oncol. 2018, 117, 634-643. [CrossRef]

168. Kemeny, N.; Huang, Y.; Cohen, A.M.; Shi, W.; Conti, J.A.; Brennan, M.F.; Bertino, J.R.; Turnbull, A.D.M.; Sullivan, D.; Stockman, J.; et al. Hepatic Arterial Infusion of Chemotherapy after Resection of Hepatic Metastases from Colorectal Cancer. N. Engl. J. Med. 1999, 341, 2039-2048. [CrossRef]

169. Kemeny, M.M.; Adak, S.; Gray, B.; Macdonald, J.S.; Smith, T.; Lipsitz, S.; Sigurdson, E.R.; O’Dwyer, P.J.; Benson, A.B. CombinedModality Treatment for Resectable Metastatic Colorectal Carcinoma to the Liver: Surgical Resection of Hepatic Metastases in Combination With Continuous Infusion of Chemotherapy-An Intergroup Study. J. Clin. Oncol. 2002, 20, 1499-1505. [CrossRef] [PubMed]

170. Lygidakis, N.J.; Sgourakis, G.; Vlachos, L.; Raptis, S.; Safioleas, M.; Boura, P.; Kountouras, J.; Alamani, M. Metastatic Liver Disease of Colorectal Origin: The Value of Locoregional Immunochemotherapy Combined with Systemic Chemotherapy Following Liver Resection. Results of a Prospective Randomized Study. Hepatogastroenterology 2001, 48, 1685-1691. [PubMed]

171. Lorenz, M.; Müller, H.-H.; Schramm, H.; Gassel, H.-J.; Rau, H.-G.; Ridwelski, K.; Hauss, J.; Stieger, R.; Jauch, K.-W.; Bechstein, W.O.; et al. Randomized Trial of Surgery Versus Surgery Followed by Adjuvant Hepatic Arterial Infusion With 5-Fluorouracil and Folinic Acid for Liver Metastases of Colorectal Cancer. German Cooperative on Liver Metastases (Arbeitsgruppe Lebermetastasen). Ann. Surg. 1998, 228, 756-762. [CrossRef]

172. Nelson, R.; Freels, S. Hepatic Artery Adjuvant Chemotherapy for Patients Having Resection or Ablation of Colorectal Cancer Metastatic to the Liver. In Cochrane Database of Systematic Reviews; The Cochrane Collaboration, Ed.; John Wiley \& Sons, Ltd.: Chichester, UK, 2004; p. 003770.

173. Kemeny, N.E.; Chou, J.F.; Boucher, T.M.; Capanu, M.; DeMatteo, R.P.; Jarnagin, W.R.; Allen, P.J.; Fong, Y.C.; Cercek, A.; D’Angelica, M.I. Updated Long-Term Survival for Patients with Metastatic Colorectal Cancer Treated with Liver Resection Followed by Hepatic Arterial Infusion and Systemic Chemotherapy: Survival for Resected Liver Metastases. J. Surg. Oncol. 2016, 113, 477-484. [CrossRef]

174. House, M.G.; Kemeny, N.E.; Gönen, M.; Fong, Y.; Allen, P.J.; Paty, P.B.; DeMatteo, R.P.; Blumgart, L.H.; Jarnagin, W.R.; D’Angelica, M.I. Comparison of Adjuvant Systemic Chemotherapy With or Without Hepatic Arterial Infusional Chemotherapy After Hepatic Resection for Metastatic Colorectal Cancer. Ann. Surg. 2011, 254, 851-856. [CrossRef] [PubMed]

175. Groot Koerkamp, B.; Sadot, E.; Kemeny, N.E.; Gönen, M.; Leal, J.N.; Allen, P.J.; Cercek, A.; DeMatteo, R.P.; Kingham, T.P.; Jarnagin, W.R.; et al. Perioperative Hepatic Arterial Infusion Pump Chemotherapy Is Associated With Longer Survival After Resection of Colorectal Liver Metastases: A Propensity Score Analysis. J. Clin. Oncol. 2017, 35, 1938-1944. [CrossRef] [PubMed]

176. Hamady, Z.Z.R.; Lodge, J.P.A.; Welsh, F.K.; Toogood, G.J.; White, A.; John, T.; Rees, M. One-Millimeter Cancer-Free Margin Is Curative for Colorectal Liver Metastases: A Propensity Score Case-Match Approach. Ann. Surg. 2014, 259, 543-548. [CrossRef]

177. Leung, M.; Gholami, S. The State of Hepatic Artery Infusion Chemotherapy in the Management of Metastatic Colorectal Cancer to the Liver. Chin. Clin. Oncol. 2019, 8, 54. [CrossRef] [PubMed]

178. Datta, J.; Narayan, R.R.; Kemeny, N.E.; D’Angelica, M.I. Role of Hepatic Artery Infusion Chemotherapy in Treatment of Initially Unresectable Colorectal Liver Metastases: A Review. JAMA Surg. 2019, 154, 768. [CrossRef] [PubMed] 
179. Osuga, K.; Maeda, N.; Higashihara, H.; Hori, S.; Nakazawa, T.; Tanaka, K.; Nakamura, M.; Kishimoto, K.; Ono, Y.; Tomiyama, N. Current Status of Embolic Agents for Liver Tumor Embolization. Int. J. Clin. Oncol. 2012, 17, 306-315. [CrossRef] [PubMed]

180. Massmann, A.; Rodt, T.; Marquardt, S.; Seidel, R.; Thomas, K.; Wacker, F.; Richter, G.M.; Kauczor, H.U.; Bücker, A.; Pereira, P.L.; et al. Transarterial Chemoembolization (TACE) for Colorectal Liver Metastases-Current Status and Critical Review. Langenbecks Arch. Surg. 2015, 400, 641-659. [CrossRef]

181. Riaz, A.; Lewandowski, R.J.; Salem, R. Locoregional Therapies for Primary and Secondary Hepatic Malignancies. In Gastrointestinal Malignancies; Bentrem, D., Benson, A.B., Eds.; Cancer Treatment and Research; Springer International Publishing: Cham, Switzerland, 2016; pp. 233-256. ISBN 978-3-319-34242-9.

182. Liapi, E.; Lee, K.-H.; Georgiades, C.C.; Hong, K.; Geschwind, J.-F.H. Drug-Eluting Particles for Interventional Pharmacology. Tech Vasc. Interv. Radiol. 2007, 10, 261-269. [CrossRef]

183. Zacharias, A.J.; Jayakrishnan, T.T.; Rajeev, R.; Rilling, W.S.; Thomas, J.P.; George, B.; Johnston, F.M.; Gamblin, T.C.; Turaga, K.K. Comparative Effectiveness of Hepatic Artery Based Therapies for Unresectable Colorectal Liver Metastases: A Meta-Analysis. PLoS ONE 2015, 10, e0139940. [CrossRef]

184. Fiorentini, G.; Sarti, D.; Nani, R.; Aliberti, C.; Fiorentini, C.; Guadagni, S. Updates of Colorectal Cancer Liver Metastases Therapy: Review on DEBIRI. Hepatic Oncol. 2020, 7, HEP16. [CrossRef]

185. Lencioni, R.; de Baere, T.; Burrel, M.; Caridi, J.G.; Lammer, J.; Malagari, K.; Martin, R.C.G.; O'Grady, E.; Real, M.I.; Vogl, T.J.; et al. Transcatheter Treatment of Hepatocellular Carcinoma with Doxorubicin-Loaded DC Bead (DEBDOX): Technical Recommendations. Cardiovasc. Interv. Radiol. 2012, 35, 980-985. [CrossRef]

186. Lewis, A.L.; Hall, B. Toward a Better Understanding of the Mechanism of Action for Intra-Arterial Delivery of Irinotecan from DC Bead ${ }^{\text {TM }}$ (DEBIRI). Future Oncol. 2019, 15, 2053-2068. [CrossRef]

187. Marcacuzco Quinto, A.; Nutu, O.-A.; San Román Manso, R.; Justo Alonso, I.; Calvo Pulido, J.; Manrique Municio, A.; García-Sesma, Á.; Loinaz Segurola, C.; Martínez Caballero, J.; Jiménez Romero, L.C. Complicaciones de la quimioembolización transarterial (QETA) en el tratamiento de los tumores hepáticos. Cirugía Española 2018, 96, 560-567. [CrossRef]

188. Xia, J.; Ren, Z.; Ye, S.; Sharma, D.; Lin, Z.; Gan, Y.; Chen, Y.; Ge, N.; Ma, Z.; Wu, Z.; et al. Study of Severe and Rare Complications of Transarterial Chemoembolization (TACE) for Liver Cancer. Eur. J. Radiol. 2006, 59, 407-412. [CrossRef]

189. Albert, M.; Kiefer, M.V.; Sun, W.; Haller, D.; Fraker, D.L.; Tuite, C.M.; Stavropoulos, S.W.; Mondschein, J.I.; Soulen, M.C. Chemoembolization of Colorectal Liver Metastases with Cisplatin, Doxorubicin, Mitomycin C, Ethiodol, and Polyvinyl Alcohol. Cancer 2011, 117, 343-352. [CrossRef] [PubMed]

190. Sanz-Altamira, P.M.; Spence, L.D.; Huberman, M.S.; Posner, M.R.; Steele, G.; Perry, L.J.; Stuart, K.E. Selective Chemoembolization in the Management of Hepatic Metastases in Refractory Colorectal Carcinoma: A Phase II Trial. Dis. Colon Rectum 1997, 40, 770-775. [CrossRef]

191. Vogl, T.J.; Gruber, T.; Balzer, J.O.; Eichler, K.; Hammerstingl, R.; Zangos, S. Repeated Transarterial Chemoembolization in the Treatment of Liver Metastases of Colorectal Cancer: Prospective Study. Radiology 2009, 250, 281-289. [CrossRef] [PubMed]

192. Yu, Q.; Zhang, L.; Fan, S.; Huang, L.; Wang, X.; Xindun, C. The Significance of Transarterial Chemoembolization Combined with Systemic Chemotherapy for Patients with KRAS Wild-Type Unresectable Metachronous Colorectal Carcinoma with Liver Metastases. J. Cancer Res. Ther. 2016, 12, 205. [CrossRef]

193. Martin, R.C.G.; Scoggins, C.R.; Schreeder, M.; Rilling, W.S.; Laing, C.J.; Tatum, C.M.; Kelly, L.R.; Garcia-Monaco, R.D.; Sharma, V.R.; Crocenzi, T.S.; et al. Randomized Controlled Trial of Irinotecan Drug-Eluting Beads with Simultaneous FOLFOX and Bevacizumab for Patients with Unresectable Colorectal Liver-Limited Metastasis: Irinotecan Intrahepatic Arterial Chemotherapy. Cancer 2015, 121, 3649-3658. [CrossRef]

194. Aliberti, C.; Fiorentini, G.; Muzzio, P.C.; Pomerri, F.; Tilli, M.; Dallara, S.; Benea, G. Trans-Arterial Chemoembolization of Metastatic Colorectal Carcinoma to the Liver Adopting DC Bead ${ }^{\circledR}$, Drug-Eluting Bead Loaded with Irinotecan: Results of a Phase II Clinical Study. Anticancer Res. 2011, 31, 4581-4587.

195. Di Noia, V.; Basso, M.; Marsico, V.; Cerchiaro, E.; Rossi, S.; D’Argento, E.; Strippoli, A.; Schinzari, G.; Iezzi, R.; Cassano, A.; et al. DEBIRI plus Capecitabine: A Treatment Option for Refractory Liver-Dominant Metastases from Colorectal Cancer. Future Oncol. 2019, 15, 2349-2360. [CrossRef]

196. Fiorentini, G.; Aliberti, C.; Tilli, M.; Mulazzani, L.; Graziano, F.; Giordani, P.; Mambrini, A.; Montagnani, F.; Alessandroni, P.; Catalano, V.; et al. Intra-Arterial Infusion of Irinotecan-Loaded Drug-Eluting Beads (DEBIRI) versus Intravenous Therapy (FOLFIRI) for Hepatic Metastases from Colorectal Cancer: Final Results of a Phase III Study. Anticancer Res. 2012, 32, $1387-1395$.

197. Campbell, A.M.; Bailey, I.H.; Burton, M.A. Tumour Dosimetry in Human Liver Following Hepatic Yttrium-90 Microsphere Therapy. Phys. Med. Biol. 2001, 46, 487-498. [CrossRef] [PubMed]

198. Kennedy, A.S.; Nutting, C.; Coldwell, D.; Gaiser, J.; Drachenberg, C. Pathologic Response and Microdosimetry of $90 \mathrm{Y}$ Microspheres in Man: Review of Four Explanted Whole Livers. Int. J. Radiat. Oncol. Biol. Phys. 2004, 60, 1552-1563. [CrossRef] [PubMed]

199. Kennedy, A.; Nag, S.; Salem, R.; Murthy, R.; McEwan, A.J.; Nutting, C.; Benson, A.; Espat, J.; Bilbao, J.I.; Sharma, R.A.; et al. Recommendations for Radioembolization of Hepatic Malignancies Using Yttrium-90 Microsphere Brachytherapy: A Consensus Panel Report from the Radioembolization Brachytherapy Oncology Consortium. Int. J. Radiat. Oncol. Biol. Phys. 2007, 68, 13-23. [CrossRef] [PubMed] 
200. Kennedy, A.S.; McNeillie, P.; Dezarn, W.A.; Nutting, C.; Sangro, B.; Wertman, D.; Garafalo, M.; Liu, D.; Coldwell, D.; Savin, M.; et al. Treatment Parameters and Outcome in 680 Treatments of Internal Radiation With Resin 90Y-Microspheres for Unresectable Hepatic Tumors. Int. J. Radiat. Oncol. Biol. Phys. 2009, 74, 1494-1500. [CrossRef] [PubMed]

201. Sangro, B.; Gil-Alzugaray, B.; Rodriguez, J.; Sola, I.; Martinez-Cuesta, A.; Viudez, A.; Chopitea, A.; Iñarrairaegui, M.; Arbizu, J.; Bilbao, J.I. Liver Disease Induced by Radioembolization of Liver Tumors: Description and Possible Risk Factors. Cancer 2008, 112, 1538-1546. [CrossRef]

202. Karanicolas, P.; Beecroft, J.R.; Cosby, R.; David, E.; Kalyvas, M.; Kennedy, E.; Sapisochin, G.; Wong, R.; Zbuk, K. Regional Therapies for Colorectal Liver Metastases: Systematic Review and Clinical Practice Guideline. Clin. Colorectal Cancer 2021, 20, 20-28. [CrossRef]

203. Van Hazel, G.; Blackwell, A.; Anderson, J.; Price, D.; Moroz, P.; Bower, G.; Cardaci, G.; Gray, B. Randomised Phase 2 Trial of SIR-Spheres ${ }^{\circledR}$ plus Fluorouracil/Leucovorin Chemotherapy versus Fluorouracil/Leucovorin Chemotherapy Alone in Advanced Colorectal Cancer: Randomised Trial of SIR-Spheres ${ }^{\circledR}$ Plus Chemotherapy in Colorectal Cancer. J. Surg. Oncol. 2004, 88, 78-85. [CrossRef]

204. Hendlisz, A.; den Eynde, M.V.; Peeters, M.; Maleux, G.; Lambert, B.; Vannoote, J.; Keukeleire, K.D.; Verslype, C.; Defreyne, L.; Cutsem, E.V.; et al. Phase III Trial Comparing Protracted Intravenous Fluorouracil Infusion Alone or With Yttrium-90 Resin Microspheres Radioembolization for Liver-Limited Metastatic Colorectal Cancer Refractory to Standard Chemotherapy. J. Clin. Oncol. 2010, 28, 3687-3694. [CrossRef]

205. van Hazel, G.A.; Heinemann, V.; Sharma, N.K.; Findlay, M.P.N.; Ricke, J.; Peeters, M.; Perez, D.; Robinson, B.A.; Strickland, A.H.; Ferguson, T.; et al. SIRFLOX: Randomized Phase III Trial Comparing First-Line MFOLFOX6 (Plus or Minus Bevacizumab) Versus MFOLFOX6 (Plus or Minus Bevacizumab) Plus Selective Internal Radiation Therapy in Patients With Metastatic Colorectal Cancer. J. Clin. Oncol. 2016, 34, 1723-1731. [CrossRef] [PubMed]

206. Dutton, S.J.; Kenealy, N.; Love, S.B.; Wasan, H.S.; Sharma, R.A. FOXFIRE Protocol: An Open-Label, Randomised, Phase III Trial of 5-Fluorouracil, Oxaliplatin and Folinic Acid (OxMdG) with or without Interventional Selective Internal Radiation Therapy (SIRT) as First-Line Treatment for Patients with Unresectable Liver-Only or Liver-Dominant Metastatic Colorectal Cancer. BMC Cancer 2014, 14, 497. [CrossRef]

207. Gibbs, P.; Gebski, V.; Van Buskirk, M.; Thurston, K.; Cade, D.N.; Van Hazel, G.A.; SIRFLOX Study Group. Selective Internal Radiation Therapy (SIRT) with Yttrium-90 Resin Microspheres plus Standard Systemic Chemotherapy Regimen of FOLFOX versus FOLFOX Alone as First-Line Treatment of Non-Resectable Liver Metastases from Colorectal Cancer: The SIRFLOX Study. BMC Cancer 2014, 14, 897. [CrossRef]

208. Wasan, H.S.; Gibbs, P.; Sharma, N.K.; Taieb, J.; Heinemann, V.; Ricke, J.; Peeters, M.; Findlay, M.; Weaver, A.; Mills, J.; et al. First-Line Selective Internal Radiotherapy plus Chemotherapy versus Chemotherapy Alone in Patients with Liver Metastases from Colorectal Cancer (FOXFIRE, SIRFLOX, and FOXFIRE-Global): A Combined Analysis of Three Multicentre, Randomised, Phase 3 Trials. Lancet Oncol. 2017, 18, 1159-1171. [CrossRef]

209. Gray, A.M.; Wolstenholme, J.; Fusco, F.; Chau, I.; Dunham, L.; Love, S.; Roberts, A.; Moschandreas, J.; Virdee, P.; Lewington, V.; et al. Quality of Life in Patients with Liver Metastases from Colorectal Cancer Treated with First-Line Selective Internal Radiotherapy (SIRT): Results from the FOXFIRE Prospective Randomized Studies. Ann. Oncol. 2017, 28, v201. [CrossRef]

210. Wasan, H.; Sharma, R.; Heinemann, V.; Sharma, N.; Taieb, J.; Ricke, J.; Peeters, M.; Findlay, M.; Virdee, P.S.; Love, S.; et al. FOXFIRE-SIRFLOX-FOXFIRE Global Prospective Randomised Studies of First-Line Selective Internal Radiotherapy (SIRT) in Patients with Liver Metastases from Colorectal Cancer: KRAS Mutation and Tumour Site Analysis. Ann. Oncol. 2017, 28 , v615. [CrossRef]

211. Gibbs, P.; Heinemann, V.; Sharma, N.K.; Taieb, J.; Ricke, J.; Peeters, M.; Findlay, M.; Robinson, B.; Jackson, C.; Strickland, A.; et al. Effect of Primary Tumor Side on Survival Outcomes in Untreated Patients With Metastatic Colorectal Cancer When Selective Internal Radiation Therapy Is Added to Chemotherapy: Combined Analysis of Two Randomized Controlled Studies. Clin. Colorectal Cancer 2018, 17, e617-e629. [CrossRef]

212. van Hazel, G.; Heinemann, V.; Sharma, N.; Taieb, J.; Ricke, J.; Peeters, M.; Findlay, M.; Gibbs, P. Impact of Primary Tumour Location on Survival in Patients with Metastatic Colorectal Cancer Receiving Selective Internal Radiation Therapy and Chemotherapy as First-Line Therapy. Ann. Oncol. 2017, 28, iii152. [CrossRef]

213. Kennedy, A.S.; Coldwell, D.; Nutting, C.; Murthy, R.; Wertman, D.E.; Loehr, S.P.; Overton, C.; Meranze, S.; Niedzwiecki, J.; Sailer, S. Resin 90Y-Microsphere Brachytherapy for Unresectable Colorectal Liver Metastases: Modern USA Experience. Int. J. Radiat. Oncol. Biol. Phys. 2006, 65, 412-425. [CrossRef]

214. Cosimelli, M.; Golfieri, R.; Cagol, P.P.; Carpanese, L.; Sciuto, R.; Maini, C.L.; Mancini, R.; Sperduti, I.; Pizzi, G.; Italian Society of Locoregional Therapies in Oncology (SITILO); et al. Multi-Centre Phase II Clinical Trial of Yttrium-90 Resin Microspheres Alone in Unresectable, Chemotherapy Refractory Colorectal Liver Metastases. Br. J. Cancer 2010, 103, 324-331. [CrossRef]

215. Sato, K.T.; Lewandowski, R.J.; Mulcahy, M.F.; Atassi, B.; Ryu, R.K.; Gates, V.L.; Nemcek, A.A.; Barakat, O.; Benson, A.; Mandal, R.; et al. Unresectable Chemorefractory Liver Metastases: Radioembolization with ${ }^{90}$ Y Microspheres—Safety, Efficacy, and Survival. Radiology 2008, 247, 507-515. [CrossRef] [PubMed]

216. Bester, L.; Meteling, B.; Pocock, N.; Pavlakis, N.; Chua, T.C.; Saxena, A.; Morris, D.L. Radioembolization versus Standard Care of Hepatic Metastases: Comparative Retrospective Cohort Study of Survival Outcomes and Adverse Events in Salvage Patients. J. Vasc. Interv. Radiol. 2012, 23, 96-105. [CrossRef] [PubMed] 
217. Seidensticker, R.; Denecke, T.; Kraus, P.; Seidensticker, M.; Mohnike, K.; Fahlke, J.; Kettner, E.; Hildebrandt, B.; Dudeck, O.; Pech, M.; et al. Matched-Pair Comparison of Radioembolization Plus Best Supportive Care Versus Best Supportive Care Alone for Chemotherapy Refractory Liver-Dominant Colorectal Metastases. Cardiovasc. Interv. Radiol. 2012, 35, 1066-1073. [CrossRef] [PubMed]

218. Benson, A.B.; Geschwind, J.-F.; Mulcahy, M.F.; Rilling, W.; Siskin, G.; Wiseman, G.; Cunningham, J.; Houghton, B.; Ross, M.; Memon, K.; et al. Radioembolisation for Liver Metastases: Results from a Prospective 151 Patient Multi-Institutional Phase II Study. Eur. J. Cancer 2013, 49, 3122-3130. [CrossRef] [PubMed]

219. Martin, L.K.; Cucci, A.; Wei, L.; Rose, J.; Blazer, M.; Schmidt, C.; Khabiri, H.; Bloomston, M.; Bekaii-Saab, T. Yttrium-90 Radioembolization as Salvage Therapy for Colorectal Cancer With Liver Metastases. Clin. Colorectal Cancer 2012, 11, 195-199. [CrossRef]

220. Hickey, R.; Lewandowski, R.; Salem, R. Yttrium-90 Radioembolization Is a Viable Treatment Option for Unresectable, Chemorefractory Colorectal Cancer Liver Metastases: Further Evidence in Support of a New Treatment Paradigm. Ann. Surg. Oncol. 2015, 22, 706-707. [CrossRef]

221. Saxena, A.; Bester, L.; Shan, L.; Perera, M.; Gibbs, P.; Meteling, B.; Morris, D.L. A Systematic Review on the Safety and Efficacy of Yttrium-90 Radioembolization for Unresectable, Chemorefractory Colorectal Cancer Liver Metastases. J. Cancer Res. Clin. Oncol. 2014, 140, 537-547. [CrossRef]

222. Mulcahy, M.F.; Mahvash, A.; Pracht, M.; Montazeri, A.H.; Bandula, S.; Martin, R.C.G.; Herrmann, K.; Brown, E.; Zuckerman, D.; Wilson, G.; et al. Radioembolization With Chemotherapy for Colorectal Liver Metastases: A Randomized, Open-Label, International, Multicenter, Phase III Trial. J. Clin. Oncol. 2021, 32, S1295. [CrossRef]

223. Kurilova, I.; Beets-Tan, R.G.H.; Flynn, J.; Gönen, M.; Ulaner, G.; Petre, E.N.; Edward Boas, F.; Ziv, E.; Yarmohammadi, H.; Klompenhouwer, E.G.; et al. Factors Affecting Oncologic Outcomes of 90Y Radioembolization of Heavily Pre-Treated Patients With Colon Cancer Liver Metastases. Clin. Colorectal Cancer 2019, 18, 8-18. [CrossRef]

224. Lam, M.G.E.H.; Abdelmaksoud, M.H.K.; Chang, D.T.; Eclov, N.C.; Chung, M.P.; Koong, A.C.; Louie, J.D.; Sze, D.Y. Safety of 90Y Radioembolization in Patients Who Have Undergone Previous External Beam Radiation Therapy. Int. J. Radiat. Oncol. Biol. Phys. 2013, 87, 323-329. [CrossRef]

225. Swierz, M.J.; Storman, D.; Riemsma, R.P.; Wolff, R.; Mitus, J.W.; Pedziwiatr, M.; Kleijnen, J.; Bala, M.M. Transarterial (Chemo)Embolisation versus No Intervention or Placebo for Liver Metastases. Cochrane Database Syst. Rev. 2020, 3, CD009498. [CrossRef]

226. Liu, F.; Liang, P.; Yu, X.; Lu, T.; Cheng, Z.; Lei, C.; Han, Z. A Three-Dimensional Visualisation Preoperative Treatment Planning System in Microwave Ablation for Liver Cancer: A Preliminary Clinical Application. Int. J. Hyperth. 2013, 29, 671-677. [CrossRef] [PubMed]

227. Al-Nimer, S.; Hanlon, A.; Cho, K.; Kalra-Lall, A.; Weunski, C.; Yanof, J.; West, K.; Martin, C. 3D Holographic Guidance and Navigation for Percutaneous Ablation of Solid Tumor. J. Vasc. Interv. Radiol. 2020, 31, 526-528. [CrossRef] [PubMed]

228. Park, B.J.; Hunt, S.J.; Martin, C.; Nadolski, G.J.; Wood, B.J.; Gade, T.P. Augmented and Mixed Reality: Technologies for Enhancing the Future of IR. J. Vasc. Interv. Radiol. 2020, 31, 1074-1082. [CrossRef] [PubMed]

229. Huber, T.C.; Miller, G.; Patrie, J.; Angle, J.F. Relationship of Antenna Work and Ablation Cavity Volume Following Percutaneous Microwave Ablation of Hepatic Tumors. J. Vasc. Interv. Radiol. 2021, 32, 536-543. [CrossRef]

230. Lyons, G.R.; Pua, B.B. Ablation Planning Software for Optimizing Treatment: Challenges, Techniques, and Applications. Tech. Vasc. Interv. Radiol. 2019, 22, 21-25. [CrossRef]

231. Edhemovic, I.; Brecelj, E.; Gasljevic, G.; Marolt Music, M.; Gorjup, V.; Mali, B.; Jarm, T.; Kos, B.; Pavliha, D.; Grcar Kuzmanov, B.; et al. Intraoperative Electrochemotherapy of Colorectal Liver Metastases. J. Surg. Oncol. 2014, 110, 320-327. [CrossRef]

232. Coletti, L.; Battaglia, V.; De Simone, P.; Turturici, L.; Bartolozzi, C.; Filipponi, F. Safety and Feasibility of Electrochemotherapy in Patients with Unresectable Colorectal Liver Metastases: A Pilot Study. Int. J. Surg. 2017, 44, 26-32. [CrossRef]

233. Gasljevic, G.; Edhemovic, I.; Cemazar, M.; Brecelj, E.; Gadzijev, E.M.; Music, M.M.; Sersa, G. Histopathological Findings in Colorectal Liver Metastases after Electrochemotherapy. PLoS ONE 2017, 12, e0180709. [CrossRef]

234. Padia, S.A.; Johnson, G.E.; Agopian, V.G.; DiNorcia, J.; Srinivasa, R.N.; Sayre, J.; Shin, D.S. Yttrium-90 Radiation Segmentectomy for Hepatic Metastases: A Multi-institutional Study of Safety and Efficacy. J. Surg. Oncol. 2021, 123, 172-178. [CrossRef]

235. Kurilova, I.; Bendet, A.; Fung, E.K.; Petre, E.N.; Humm, J.L.; Boas, F.E.; Crane, C.H.; Kemeny, N.; Kingham, T.P.; Cercek, A.; et al. Radiation Segmentectomy of Hepatic Metastases with Y-90 Glass Microspheres. Abdom. Radiol. 2021, 46, 3428-3436. [CrossRef]

236. Bonney, G.K.; Chew, C.A.; Lodge, P.; Hubbard, J.; Halazun, K.J.; Trunecka, P.; Muiesan, P.; Mirza, D.F.; Isaac, J.; Laing, R.W.; et al. Liver Transplantation for Non-Resectable Colorectal Liver Metastases: The International Hepato-Pancreato-Biliary Association Consensus Guidelines. Lancet Gastroenterol. Hepatol. 2021, 6, 933-946. [CrossRef]

237. Hagness, M.; Foss, A.; Line, P.-D.; Scholz, T.; Jørgensen, P.F.; Fosby, B.; Boberg, K.M.; Mathisen, Ø.; Gladhaug, I.P.; Egge, T.S.; et al Liver Transplantation for Nonresectable Liver Metastases From Colorectal Cancer. Ann. Surg. 2013, 257, 800-806. [CrossRef] [PubMed]

238. Dueland, S.; Syversveen, T.; Solheim, J.M.; Solberg, S.; Grut, H.; Bjørnbeth, B.A.; Hagness, M.; Line, P.-D. Survival Following Liver Transplantation for Patients With Nonresectable Liver-Only Colorectal Metastases. Ann. Surg. 2020, 271, 212-218. [CrossRef] [PubMed] 
239. Calandri, M.; Odisio, B.C. Tailoring Ablation Strategies for Colorectal Liver Metastases Based upon Rat Sarcoma Viral Oncogene Mutation Status. Chin. Clin. Oncol. 2019, 8, 51. [CrossRef]

240. Kopetz, S.; Desai, J.; Chan, E.; Hecht, J.R.; O’Dwyer, P.J.; Maru, D.; Morris, V.; Janku, F.; Dasari, A.; Chung, W.; et al. Phase II Pilot Study of Vemurafenib in Patients With Metastatic BRAF-Mutated Colorectal Cancer. J. Clin. Oncol. 2015, 33, 4032-4038. [CrossRef] [PubMed]

241. Yamashita, S.; Chun, Y.S.; Kopetz, S.E.; Vauthey, J.-N. Biomarkers in Colorectal Liver Metastases. Br. J. Surg. 2018, 105, 618-627. [CrossRef] [PubMed]

242. Battaglin, F.; Naseem, M.; Lenz, H.-J.; Salem, M.E. Microsatellite Instability in Colorectal Cancer: Overview of Its Clinical Significance and Novel Perspectives. Clin. Adv. Hematol. Oncol. 2018, 16, 735-745.

243. André, T.; Shiu, K.-K.; Kim, T.W.; Jensen, B.V.; Jensen, L.H.; Punt, C.; Smith, D.; Garcia-Carbonero, R.; Benavides, M.; Gibbs, P.; et al. Pembrolizumab in Microsatellite-Instability-High Advanced Colorectal Cancer. N. Engl. J. Med. 2020, 383, $2207-2218$. [CrossRef]

244. Chalabi, M.; Fanchi, L.F.; Dijkstra, K.K.; Van den Berg, J.G.; Aalbers, A.G.; Sikorska, K.; Lopez-Yurda, M.; Grootscholten, C.; Beets, G.L.; Snaebjornsson, P.; et al. Neoadjuvant Immunotherapy Leads to Pathological Responses in MMR-Proficient and MMR-Deficient Early-Stage Colon Cancers. Nat. Med. 2020, 26, 566-576. [CrossRef]

245. Hu, H.; Kang, L.; Zhang, J.; Wu, Z.; Wang, H.; Huang, M.; Lan, P.; Wu, X.; Wang, C.; Cao, W.; et al. Neoadjuvant PD-1 Blockade with Toripalimab, with or without Celecoxib, in Mismatch Repair-Deficient or Microsatellite Instability-High, Locally Advanced, Colorectal Cancer (PICC): A Single-Centre, Parallel-Group, Non-Comparative, Randomised, Phase 2 Trial. Lancet Gastroenterol. Hepatol. 2021, S2468125321003484. [CrossRef]

246. de'Angelis, N.; Baldini, C.; Brustia, R.; Pessaux, P.; Sommacale, D.; Laurent, A.; Le Roy, B.; Tacher, V.; Kobeiter, H.; Luciani, A.; et al. Surgical and Regional Treatments for Colorectal Cancer Metastases in Older Patients: A Systematic Review and Meta-Analysis. PLoS ONE 2020, 15, e0230914. [CrossRef] [PubMed] 